\title{
The Short-Run Macroeconomics of Aid Inflows: Understanding the Interaction of Fiscal and Reserve Policy
}

\author{
Andrew Berg, Tokhir Mirzoev, \\ Rafael Portillo, and Luis-Felipe Zanna
}


(C) 2010 International Monetary Fund

$\mathrm{WP} / 10 / 65$

\title{
IMF Working Paper
}

Research Department

\section{The Short-Run Macroeconomics of Aid Inflows: Understanding the Interaction of Fiscal and Reserve Policy}

\author{
Prepared by Andrew Berg, Tokhir Mirzoev, Rafael Portillo, and Luis-Felipe Zanna*
}

Authorized for distribution by Andrew Berg

March 2010

\begin{abstract}
This Working Paper should not be reported as representing the views of the IMF. The views expressed in this Working Paper are those of the author(s) and do not necessarily represent those of the IMF or IMF policy. Working Papers describe research in progress by the author(s) and are published to elicit comments and to further debate.

We develop a tractable open-economy new-Keynesian model with two sectors to analyze the short-term effects of aid-financed fiscal expansions. We distinguish between spending the aid, which is under the control of the fiscal authorities, and absorbing the aid - using the aid to finance a higher current account deficit—which is influenced by the central bank's reserves policy when access to international capital markets is limited. The standard treatment of the transfer problem implicitly assumes spending equals absorption. Here, in contrast, a policy mix that results in spending but not absorbing the aid generates demand pressures and results in an increase in real interest rates. It can also lead to a temporary real depreciation if demand pressures are strong enough to threaten external balance. Certain features of low income countries, such as limited participation in domestic financial markets, make a real depreciation more likely by amplifying demand pressures when aid is spent but not absorbed. The results from our model can help understand the recent experience of Uganda, which saw an increase in government spending following a surge in aid yet experienced a real depreciation and an increase in real interest rates.
\end{abstract}

JEL Classification Numbers:E58, E63, E35, F41

Keywords: Aid; transfer problem; fiscal policy; monetary policy; real exchange rate; Africa Author's E-Mail Address:rportillo@imf.org

\footnotetext{
* The authors would like to thank Chris Adam, Olivier Blanchard, Mai Dao, Peter Montiel, Steve O'Connell, Chris Papageorgiou, Mauro Roca, David Romer, and Antonio Spilimbergo for helpful comments and suggestions, as well as seminar participants at the Banque de France and the IMF Workshop on Frameworks for Policy Analysis in Low-Income Countries. All errors remain ours.
} 


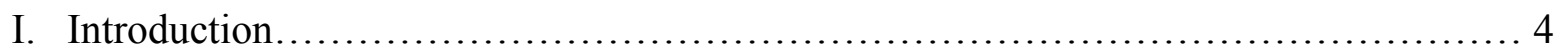

II. The Aid Surge in Uganda...................................................... 7

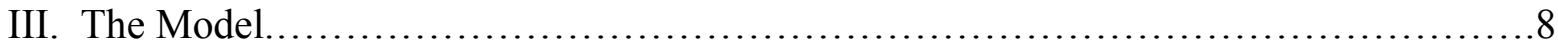

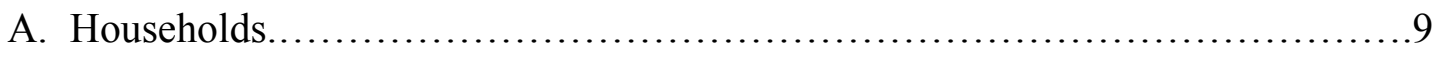

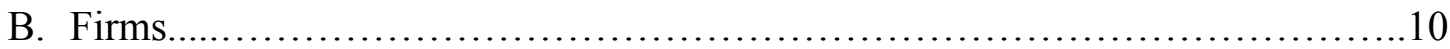

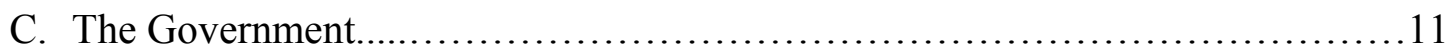

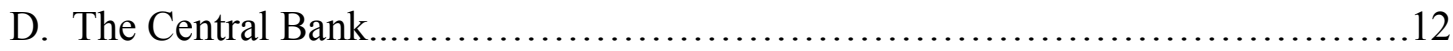

E. Equilibrium Conditions....................................................

F. The Steady State........................................................... 14

G. The Log-Linearized Version of the Model....................................14

IV. Fiscal and Reserve Policy Interaction Under Flexible Prices..........................17

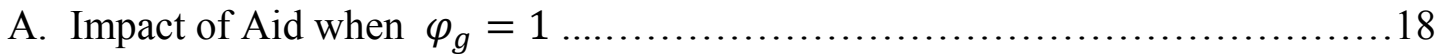

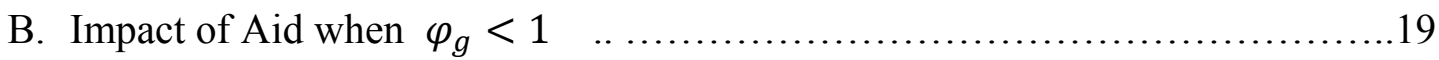

C. Reserves Policy, the Real Exchange Rate and the Natural Rate of Interest.........20

V. Policy Interactions Under Sticky Prices...............................................20

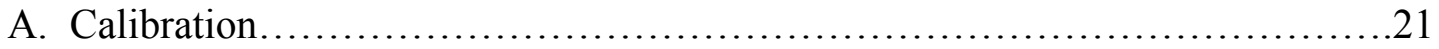

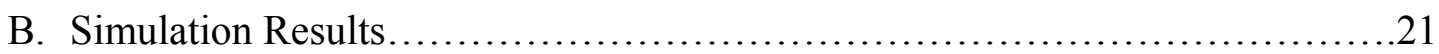

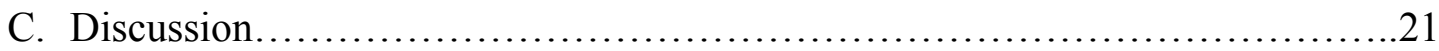

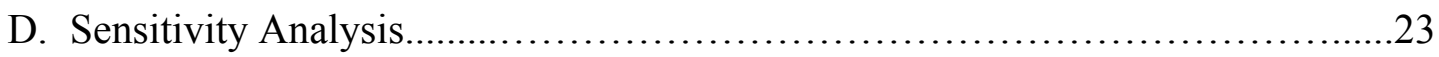

E. The Role of Monetary Policy ..................................................

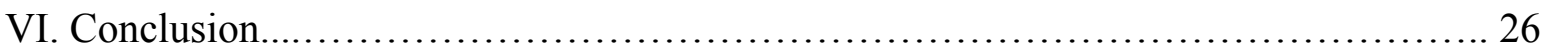

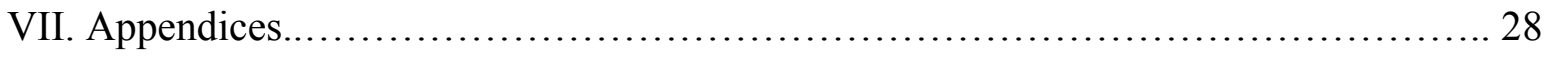

A. The flexible price solution when the capital account is closed..................28

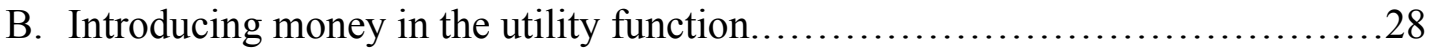

Tables

Table 1. Selected Macroeconomic Variables, Uganda, 1998-2004.......................30

Table 2. Benchmark: Calibrated Parameters................................................... 




Table 4. Sensitivity Analysis (2)......................................................

Figures

Figure 1. Possible Fiscal and Reserve Policy Combinations.............................34

Figure 2. External Balance, Internal Balance, and Labor Market Equilibrium..............35

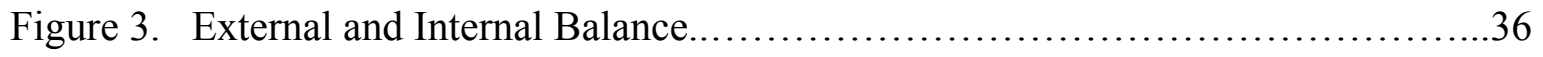

Figure 4. Alternative Spend and Absorb Scenarios......................................... 37

Figure 5. Alternative Spend and Absorb Scenarios (2).................................... 38

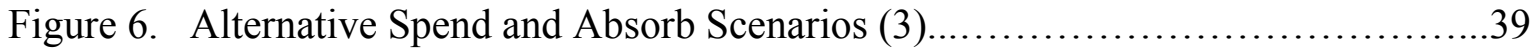

Figure 7. Alternative Reserve Policy Responses: Impact on $\hat{\mathrm{s}}_{\mathrm{t}}^{\mathrm{n}}$ and $\hat{r}_{t}^{n} \ldots \ldots \ldots \ldots \ldots \ldots \ldots . . \ldots . \ldots . \ldots . \ldots$

Figure 8. Spend and Absorb Scenario (Percent Deviations from Steady State).............41

Figure 9. Spend, No Absorption Scenario (Percent Deviations from Steady State).........42

Figure 10. External Balance, Internal Balance and Labor Market Equilibrium Revisited..43

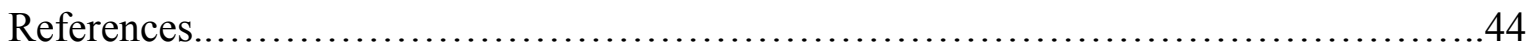




\section{INTRODUCTION}

What are the short run effects of aid flows? The standard answer to this question is provided by the time-honored literature on the "transfer problem." "According to this literature, the representative agent of the recipient country will use the aid to increase its expenditure on both traded and non-traded goods, with the increase in spending automatically reflected in an increase in the country's absorption (an increase in the current account deficit net of the transfer). ${ }^{2}$ In this context, an appreciation of the real exchange rate is required to shift demand toward traded goods and supply toward non-traded goods, and therefore ensure both internal balance-the equilibrium in the market for non-traded goods - and external balance — the satisfaction of the balance of payments. The analysis is similar if the government is the direct recipient of the aid, rather than the representative agent, in which case the higher absorption corresponds to higher government spending.

Little attention is paid to how the reserve policy of the central bank may affect the impact of aid. ${ }^{3}$ This neglect becomes a serious handicap when analyzing the recent experience of African countries. In the case of Uganda, aid inflows and aid-financed government spending increased considerably during the first half of the decade, yet the current account deficit net of aid did not increase (Table 1). Instead, the additional aid ended up accumulated as reserves. In addition, the real exchange rate depreciated and the country experienced a considerable increase in real interest rates - a variable that is often ignored in the analysis of transfers. As documented in Berg, and others (2007), other African countries with large aid surges also experienced a fiscal expansion, a large accumulation of reserves, and a real depreciation.

The above experience suggests that, contrary to the standard treatment of the transfer problem, the distinction between the spending and the absorption of the aid is crucial. ${ }^{4}$ While the former is determined by the fiscal policy response, the later is influenced by the reserve policy of the central bank-provided access to international capital markets is limited. In the case of Uganda, aid was spent but not absorbed.

In practice, there is no institutional arrangement between the government and the central bank that ensures coordination of the two policy responses. In a canonical aid transaction, the foreign exchange (FX) from aid accrues to the government, which sells it to the central bank in exchange for a local currency deposit. The central bank in turn decides on its own whether to accumulate the FX as reserves, and whether such accumulation should be sterilized, as it was in Uganda. Depending on the policy mix, there can be several possible combinations of spending and absorption (Figure 1).

\footnotetext{
${ }^{1}$ The modern literature on the topic started with the famous Keynes-Ohlin (1929) controversy. Brakman and Van Marrewjik (1998) thoroughly review the (mostly static) literature; Devereux and Smith (2007) provide a dynamic treatment.

${ }^{2}$ Ohlin (1929) is the first to emphasize the role of the non-traded sector. See also McDougall (1965) and Brock (1996). Most of the literature focuses on the (endogenous) response of the terms of trade rather than the real exchange rate. Because terms of trade tend to be exogenous in low-income countries, which typically have little market power in their export markets, we abstract from this channel in our analysis.

${ }^{3}$ The exception to this claim is the analysis of transfers under the gold standard, where it is well understood that some accumulation of reserves is necessary to accommodate the required increase in the domestic price level.

${ }^{4}$ The distinction between spending and absorption is reminiscent of the separation between the "budgetary" and the "transfer" problem in Keynes (1929).
} 
In this paper we provide a framework for thinking about the macroeconomics of aid flows, centered on the fiscal/reserve policy interaction. To our knowledge, there has been little work on this interaction in the open economy macro literature. ${ }^{5}$ Given the surprising behavior of the real exchange rate, and the simultaneous increase in real interest rates, we study whether certain combinations of fiscal and reserve policy can account for this joint behavior.

We present our analysis in the context of a tractable two sector dynamic general equilibrium model with nominal rigidities. Our model conforms with the new-Keynesian paradigm but emphasizes important features of low income countries: little market power in export markets, limited international capital mobility, consumers' limited participation in domestic financial markets, and-as an extension—-potentially limited flexibility in the reallocation of labor across sectors. We also extend the policy set of the central bank to include two rules: the standard monetary policy rule and a separate rule determining the rate of reserve accumulation. Given the model's tractability, we can represent the short run equilibrium using a graphic representation of external balance, internal balance and the labor market. ${ }^{6}$

With the help of our model we show that a policy combination that results in spending but not absorbing the aid can generate both an increase in real interest rates and, under certain conditions, a real exchange rate depreciation. The starting intuition for our results is that spending but not absorbing the aid is akin to a domestically-financed fiscal expansion: public spending increases but the foreign exchange from the aid is not being used to increase the country's external financing. The increase in spending must therefore come at the expense of the private sector, which is crowded out. Another way of restating the same idea is that aid is being "used" twice: once to increase government spending, and once to increase the stock of reserves. Note that this intuition also justifies the choice of a new-Keynesian framework with non-Ricardian features - in this case limited participation in domestic financial markets-to study the short run macroeconomics of aid flows.

The results from the model can be summarized as follows:

- A policy mix that results in spending and absorbing the aid leads to an appreciation of the natural real exchange rate and little movement in the natural rate of interest, where "natural" denotes the flexible-price equilibrium values. In contrast, a policy that results in spending without absorption moderates the appreciation of the natural real exchange rate and increases the natural rate of interest. The appreciation is moderated because there is no increase in external financing, while the rise in the natural rate of interest reflects the crowding out of the private sector.

- Once we introduce nominal rigidities in the non-traded sector, the increase in the natural rate of interest implies that spending but not absorbing the aid generates demand pressures, i.e., temporary increases in inflation and the aggregate output gap. This is a well known result of the standard closed-economy new-Keynesian model in which monetary policy is not optimal.

\footnotetext{
${ }^{5}$ The framework presented here-the distinction between spending and absorption of aid — has been used for policy analysis in Berg, and others (2007) and a number of subsequent IMF (and non-IMF) policy papers. Buffie, and others (2010) critique some of these analyses.

${ }^{6}$ This is in the tradition of work by Salter (1959) and Swann (1960) on the "dependent economy" model. See Dornbusch (1974).
} 
Because our model is isomorphic to that setup when the capital account is closed, and we assume a standard Taylor rule in our benchmark specification, the same result applies here. ${ }^{7}$

- Demand pressures are associated with a more depreciated real exchange rate relative to the flexible-price case. They result in an increase in aggregate labor demand and therefore generate an increase in real wages. This requires a more depreciated real exchange rate—relative to its "natural" value—to guarantee external balance. ${ }^{8}$

For the real exchange rate to depreciate in absolute terms, demand-related pressures must dominate the "natural" real appreciation. We use this distinction to clarify how various features of the model affect the results. Limited participation in domestic financial markets increases the likelihood of a real depreciation because it amplifies demand pressures. The same holds if monetary policy is loosened as a result of incomplete sterilization of reserves, whereas a more aggressive monetary policy (a higher coefficient on inflation in the Taylor rule) will have the opposite effect. On the other hand, the natural appreciation becomes smaller if the share of government spending on traded goods increases. Also, labor market frictions increase the magnitude of the natural appreciation required to reallocate labor across sectors.

When we calibrate the model to Uganda, simulate a temporary aid increase, and assume aid is spent but not absorbed, the model generates a temporary real depreciation and an increase in the real interest rate. The former result is robust to some of the variations considered, including changes in the specification of preferences and plausible variations in monetary policy. However, once the capital account is open, the mapping between reserve accumulation and absorption is considerably weakened. As a result, aid invariably leads to a real appreciation, unless the accumulation of reserves is not fully sterilized. While this is an important caveat, the assumption of limited capital mobility is broadly consistent with the behavior of the capital account in Uganda following the aid surge.

The model is not designed to match the quantitative dynamic behavior of macro variables in Uganda. Before proceeding in that direction, it is important to understand the different transmission mechanisms of aid in the short run, a gap this paper intends to fill.

To our knowledge, this is one of the first papers to apply DSGE-type models to study the macroeconomics of low income countries. ${ }^{9}$ In the aid literature, our paper is closely related to Buffie, and others (2008) and Adam, and others (2009), who also discuss the role of reserve policy in the transmission of aid shocks. Their models typically feature currency substitution and fiscal dominance, which conflates the direct impact of aid with passive changes in monetary policy and currency-demand induced capital flows. While certainly useful, their models are too stylized to serve

\footnotetext{
${ }^{7}$ As discussed in Woodford (2003, chapter 4), this result stems from monetary policy—-the interest rate rule—not responding directly to changes in the natural rate of interest. In Woodford's terms, there is no positive shift in the intercept term of the interest rate feedback rule.

${ }^{8}$ This result is reminiscent of the Mundell-Fleming model with limited capital mobility (see chapter 2 in Agenor and Montiel (2008)). In that model, a domestically-financed fiscal expansion requires a real depreciation if the increase in the demand for imports - as a result of the effects of the fiscal expansion on consumption — threatens external balance. In our model, the fiscal expansion results in an increase in real wages, and the pressures on external balance come mainly from the impact of higher wages on the supply of exports.

${ }^{9}$ An exception is Peiris and Saaxegard (2007), who estimate a DSGE model for Mozambique. We believe a systematic, careful, application of these models to low income countries is long overdue.
} 
as a benchmark: sectoral output is typically given and nominal rigidities are given a cursory treatment. In addition, fiscal dominance does not seem a natural assumption for countries like Uganda, with low inflation and strong commitment to short term nominal targets. Prati, and Tressel (2005) also analyze the role of reserve accumulation in a two-period real model with a production externality in the traded sector. Their model focuses on optimal reserve policy and does not address the issue of a real exchange rate depreciation. ${ }^{10}$

Recently, other papers also look at the impact of aid on the real exchange rate and other aggregate variables (Arellano, and others (2009), Cerra, and others (2008), Chatterjee and Turnovsky (2007)). These are real models, with a focus on the medium-to-long run, and do not permit a rich discussion of the interaction of fiscal and reserve policy.

Our work is also related to an older literature on "counterpart funds", the local currency proceeds from the sale within the aid-recipient country of in-kind transfers such as food aid (Khatkhate (1963), Roemer (1988), among others). While these papers had identified some of the mechanisms described here, they lacked a coherent modeling framework to make sense of the different policy responses.

Finally, on the fiscal front, our work is related to recent papers on the analysis of fiscal policy in new-Keynesian closed economy models (Gali, Lopez-Salido, and Valles (2007), Monacelli and Perotti (2008)). These papers emphasize limited participation or non-standard preferences in helping these models match the stylized facts of fiscal shocks in industrialized countries. We find that these features are also important to account for real exchange rate behavior in our framework. In an open economy model different from ours, Corsetti, Meier, and Muller (2009) also find a real depreciation following a debt financed fiscal expansion. Their result is based on a different mechanism: fiscal expansions that are associated with expected spending reversals can lead to a decrease in long-run real interest rates and a depreciation of the real exchange through uncovered interest parity.

Our paper is organized as follows. Section 2 briefly discusses the experience of Uganda. Section 3 presents the model while section 4 focuses on the short-run equilibrium when prices are flexible. Section 5 adds nominal rigidities, and discusses the calibration and simulated results. Finally, section 6 concludes.

\section{The AID Surge In Uganda}

To provide some motivation and context for our approach, we briefly describe the experience of Uganda-summarized in Table 1. Starting in 2000, this country experienced a sustained increase in aid flows. Net aid, defined as the sum of gross aid flows and debt relief minus debt service and arrears clearance, increased by about 3 percentage points of GDP (on average) during 2000-2004, with a subsequent fall below pre-surge levels after 2005. In present value terms, the surge represented 11 percent of Uganda's GDP in 2000-2001; by way of historical comparison, the transfer associated with the Franco-Prussian war indemnity - the largest transfer in history-represented 25 percent of the French economy in 1870 (Devereux and Smith (2007)). Most of the increase took the form of budget support rather than project aid (Berg, and others (2007)).

\footnotetext{
${ }^{10}$ The relation between real interest rates and the real exchange rate in our model is also reminiscent of the work by Calvo, Reinhart, and Vegh (1995).
} 
The surge to Uganda coincided with a sharp increase in overall aid to sub-Saharan Africa over the same period, up 42 percent in real terms from 1999 to 2004 (IMF (2008a)). This increase reflected renewed donor enthusiasm for aid in the context of the UN Millennium Development Goals campaign, the end of a post-cold-war decline in aid, and the implementation of the highly-indebted poor countries (HIPC) debt relief initiative. Uganda benefited from this trend because of its successful track record in the 1990s, pre-existing strong policy regime, and good relationships with major donors, all of which made it an attractive target for additional assistance. ${ }^{11}$

Following the aid surge, fiscal authorities responded by increasing public spending (net of interest payments on foreign debt) by an average of 2.3 percentage points of GDP over the same period, with the difference being used to improve the fiscal balance. ${ }^{12}$ Most of the foreign exchange flow associated with the aid was accumulated as reserves by the central bank ( 2.3 percent increase), with the difference financing a higher current account deficit before of aid ( 0.6 percent). Only a small fraction of the increase in reserves resulted in an increase in base money growth $(0.3$ percent of GDP)—in other words almost all was sterilized.

The contrast between the fiscal and the reserve response reflected the de facto separation of policy objectives between the government and the central bank. The increase in government spending was consistent with the authorities' goal of providing public services and implementing investment projects, while also satisfying the donors demand that aid be used in the first place. On the other hand, the reserve policy response reflected the central bank's concern with "external competitiveness".

Against this backdrop, the real exchange rate depreciated considerably, most of it on account of a nominal depreciation. It is likely that some of the real depreciation reflected the worsening of the terms of trade, which started before the aid surge. However, back-of-the-envelope calculations in Berg, and others (2007) suggest the additional financing provided by the aid surge was much larger than the direct income effect of the terms-of-trade change. Finally, both nominal and (ex-post) real Treasury-bill rates increased by about 200 basis points during the aid-surge period; while 6-month and 1 year rates increased by about 500 and 600 basis points, respectively.

We now proceed with the description and analysis of the model, before returning to simulations that capture some of these stylized facts.

\section{THE MODEL}

In this section we present our small open economy model, where the only source of uncertainty is a shock to foreign aid. The economy has two goods, a traded good $(T)$ and a non-traded good $(N)$, and consists of the following agents: i) households; ii) firms; iii) a central bank in charge of monetary policy and reserve accumulation; and iv) a fiscal authority.

\footnotetext{
${ }^{11}$ According to informal discussions with government officials, donors were so enthusiastic that in 2005 the Ugandan authorities deliberately turned down some grants for fear of the macroeconomic impact.

${ }^{12}$ The 3.0 percent figure is calculated using Uganda's balance of payments data. Instead, net aid derived from the fiscal accounts increased by 2.7 percentage points. The difference results from the channeling of some flows directly to the private sector.
} 


\section{A. Households}

There is a continuum of households $[0,1]$, all valuing consumption and hours worked. For any household $j$, consumption is given by a standard CES basket:

$$
c_{t}^{j}=\left[\varphi^{\frac{1}{\chi}}\left(c_{t}^{j N}\right)^{\frac{\chi-1}{\chi}}+(1-\varphi)^{\frac{1}{\chi}}\left(c_{t}^{j T}\right)^{\frac{\chi-1}{\chi}}\right]^{\frac{\chi}{\chi-1}},
$$

which implies the consumer price index $(\mathrm{CPI}) P_{t}=\left(\varphi\left(P_{t}^{N}\right)^{1-\chi}+(1-\varphi)\left(P_{t}^{T}\right)^{1-\chi}\right)^{\frac{1}{1-\chi}} \cdot P_{t}^{T}$ and $P_{t}^{N}$ correspond to the prices of the goods, $\chi$ denotes the elasticity of substitution between traded and non-traded goods, and $\varphi$ is the degree of home bias in consumption. Equation (1) implies the following demand functions for traded and non-traded goods:

$$
c_{t}^{j N}=\varphi\left(\frac{P_{t}^{N}}{P_{t}}\right)^{-\chi} c_{t}^{j}=\varphi\left(p_{t}^{N}\right)^{-\chi} c_{t}^{j} ; \quad \text { and } \quad c_{t}^{j T}=(1-\varphi)\left(\frac{S_{t} P_{t}^{T *}}{P_{t}}\right)^{-\chi} c_{t}^{j} .
$$

Households differ in their access to financial markets. A fraction $\mathfrak{p}$ trade in asset markets, which allows them to smooth consumption in a forward looking manner. These asset holders are indexed by the superscript " $a$ ". The remaining households - the fraction $(1-\mathfrak{p})$ - have no assets and fully consume their current labor income. They are indexed by the superscript " $h$." We now describe the optimization problem faced by each type of agent.

Asset Holders The representative asset holder maximizes expected life-time utility:

$$
E_{0} \sum_{t=0}^{\infty} \beta^{t}\left[\log \left(c_{t}^{a}\right)-\frac{\varkappa}{1+\psi}\left(l_{t}^{a}\right)^{1+\psi}\right]
$$

where $l_{t}^{a}$ is the amount of labor supplied and $\psi$ is the inverse of the labor supply elasticity. His budget constraint, deflated by the domestic CPI, is given by:

$$
c_{t}^{a}+b_{t}^{a c}+s_{t} b_{t}^{a *}=w_{t} l_{t}^{a}+i_{t-1} \frac{b_{t-1}^{a c}}{\pi_{t}}+s_{t} i^{*} b_{t-1}^{a *}-s_{t} Q\left(b_{t}^{a *}\right)+\Omega_{t}^{a N}-\tau,
$$

where $b_{t}^{a c}$ is the saver's real holdings of domestic bonds issued by the government, which pay a "gross" nominal interest rate $i_{t}$; and $b_{t}^{a *}$ denotes his holdings of foreign assets deflated by the foreign price index $\left(P_{t}^{*}\right)$, which pay a gross nominal international interest rate $i^{*}$ and are subject to portfolio adjustment costs $Q\left(b_{t}^{a *}\right)$. The variable $s_{t}$ is the CPI-based real exchange rate $\left(s_{t}=\frac{S_{t} P_{t}^{*}}{P_{t}}\right)$, where $S_{t}$ is the nominal exchange rate; $\pi_{t}$ is gross domestic inflation $\left(\pi_{t}=\frac{P_{t}}{P_{t-1}}\right) ; w_{t}$ is the real wage; $\Omega_{t}^{a N}$ denotes asset holders' profits from domestic firms in the non-traded sector; and $\tau$ is a real lump sum tax levied by the government. ${ }^{13}$ Utility maximization results in the following first order conditions:

$$
\frac{1}{c_{t}^{a}}=\beta E_{t}\left[\left(\frac{1}{c_{t+1}^{a}}\right)\left(\frac{i_{t}}{\pi_{t+1}}\right)\right],
$$

\footnotetext{
${ }^{13}$ We assume foreign inflation $\pi^{*}$ is constant and equal to one.
} 


$$
\begin{gathered}
\frac{1}{c_{t}^{a}}=\beta E_{t}\left\{\left(\frac{1}{c_{t+1}^{a}}\right)\left(\frac{s_{t+1}}{s_{t}}\right)\left[\frac{i^{*}}{1+Q^{\prime}\left(b_{t}^{a *}\right)}\right]\right\}, \\
\varkappa\left(l_{t}^{a}\right)^{\psi}=\frac{w_{t}}{c_{t}^{a}} .
\end{gathered}
$$

Portfolio adjustment costs are given by $Q\left(b_{t}^{a *}\right)=\frac{v}{2}\left(b_{t}^{a *}-b^{a *}\right)^{2}$, where $b^{a *}$ is the steady-state value of the foreign assets. These costs ensure stationarity of $b_{t}^{a *}$ and allow us to model various degrees of international capital mobility. ${ }^{14}$ When $v<<\infty$, a sterilized foreign exchange rate intervention will influence the exchange rate: ceteris paribus, by reducing $b_{t}^{a *}$, a purchase of foreign exchange with domestic bonds will increase expected returns on foreign assets—net of adjustment costs—and cause a nominal depreciation. ${ }^{15}$

Non-Asset Holders Households that do not have access to asset markets maximize the same lifetime utility function as in (3) but subject to a static budget constraint:

$$
c_{t}^{h}=w_{t} l_{t}^{h}-\tau .^{h}
$$

The optimization program for these consumers reduces to a single first order condition:

$$
\varkappa\left(l_{t}^{h}\right)^{\psi}=\frac{w_{t}}{c_{t}^{h}} .
$$

Aggregation we define aggregate consumer-related variables as:

$$
x_{t}=\mathfrak{p} x_{t}^{a}+(1-\mathfrak{p}) x_{t}^{h} \text { for } x_{t}=\left(c_{t}, c_{t}^{N}, c_{t}^{T}, l_{t}, b_{t}^{*}, b_{t}^{c}, \Omega_{t}^{N}\right) .
$$

\section{B. Firms}

Non-traded goods sector The non-traded good $y_{t}^{N}$ is a composite good made from a continuum of varieties—indexed by $i \in[0,1]$ —satisfying $y_{t}^{N}=\left(\int_{0}^{1} y_{i t}^{N} \frac{\theta-1}{\theta} d i\right)^{\frac{\theta}{\theta-1}}$, where $\theta$ is the elasticity of substitution between varieties. The demand for variety $i$ is given by:

$$
y_{i t}^{N}=\left(\frac{P_{i t}^{N}}{P_{t}^{N}}\right)^{-\theta} y_{t}^{N}
$$

with $P_{t}^{N}$ defined as $P_{t}^{N}=\left(\int_{0}^{1} P_{i t}^{N 1-\theta} d i\right)^{\frac{1}{1-\theta}}$. The non-traded sector features monopolistic competition, with each firm producing a variety. Production by firm $i$ is given by:

$$
y_{i t}^{N}=z^{N}\left(l_{i t}^{N}\right)^{\alpha},
$$

\footnotetext{
${ }^{14}$ See Schmitt-Grohe and Uribe (2003) for alternative methods to ensure stationarity of net foreign assets.

${ }^{15}$ Sterilized interventions affect the exchange rate because private foreign assets enter the portfolio adjustment cost function $Q\left(b_{t}^{a *}\right)$.
} 
where $l_{i t}^{N}$ is the amount of of labor employed, $\alpha$ is the labor share and $z^{N}$ is a productivity parameter. The monopolist also faces price adjustment costs that are similar to Rotemberg (1982):

$\digamma\left(p_{t}^{N}, y_{t}^{N}, \pi_{i t}^{N}\right)=p_{t}^{N} \frac{\zeta}{2}\left(\pi_{i t}^{N}-1\right)^{2}$, where

$$
\pi_{i t}^{N}=\pi_{t} \frac{p_{i t}^{N}}{p_{i t-1}^{N}} \quad \text { and } \quad p_{i t}^{N}=\frac{P_{i t}^{N}}{P_{t}} .
$$

The monopolist chooses $p_{i t}^{N}$ to maximize its real discounted flow of profits:

$$
E_{0} \sum_{t=0}^{\infty} J_{t}\left[p_{i t}^{N}\left(\frac{p_{i t}^{N}}{p_{t}^{N}}\right)^{-\theta} y_{t}^{N}(1+\iota)-w_{t}^{N}\left(\frac{p_{i t}^{N}}{p_{t}^{N}}\right)^{-\frac{\theta}{\alpha}}\left(\frac{y_{t}^{N}}{z^{N}}\right)^{\frac{1}{\alpha}}-\digamma\left(p_{t}^{N}, y_{t}^{N}, \pi_{i t}^{N}\right)-\iota p_{t}^{N} y_{t}^{N}\right]
$$

where $J_{t}=\beta \frac{c_{t}^{a}}{c_{t+1}^{a}}$. Each firm receives a subsidy $\iota$, which is financed with a tax common to the entire sector. ${ }^{16}$ Focusing on a symmetric equilibrium, the first order condition is the following:

$$
\pi_{t}^{N}\left(\pi_{t}^{N}-1\right)=\beta E_{t}\left[\frac{c_{t}^{a}}{c_{t+1}^{a}} \pi_{t+1}^{N}\left(\pi_{t+1}^{N}-1\right)\right]+\frac{1}{\zeta}\left[\frac{\theta}{(1+\iota)(\theta-1)}\left(\frac{w_{t}^{N}}{p_{t}^{N}}\right) \frac{\left(y_{t}^{N}\right)^{\frac{1-\alpha}{\alpha}}}{\left(z^{N}\right)^{\frac{1}{\alpha}}}-1\right]
$$

Traded goods sector The traded goods sector features perfect competition and flexible prices. We assume the law of one price holds: $P_{t}^{T}=S_{t} P_{t}^{T *}$, where $P_{t}^{T *}$ is the foreign price of traded goods.

Production by firm $j$ is the following:

$$
y_{i t}^{T}=z^{T}\left(l_{i t}^{T}\right)^{\alpha} .
$$

The representative firm chooses $l_{i t}^{T}$ to maximize real profits: $E_{0} \sum_{t=0}^{\infty} J_{t}\left[s_{t} z^{T}\left(l_{i t}^{T}\right)^{\alpha}-w_{t}^{T} l_{i t}^{T}\right]$, which leads to the following first order condition:

$$
\frac{w_{t}^{T}}{s_{t}}=\frac{\left(y_{t}^{T}\right)^{\frac{1-\alpha}{\alpha}}}{\left(z^{T}\right)^{\frac{1}{\alpha}}}
$$

\section{The Government}

The government spends on a basket of traded and non-traded goods:

$$
g_{t}=\min \left(\frac{g_{t}^{N}}{\varphi_{g}}, \frac{g_{t}^{T}}{1-\varphi_{g}}\right)
$$

which implies the following government price index-measured in real terms:

$$
\frac{P_{t}^{g}}{P_{t}}=p_{t}^{g}=\left(\varphi_{g} p_{t}^{N}+\left(1-\varphi_{g}\right) s_{t}\right)
$$

\footnotetext{
${ }^{16}$ This ensures that distortions arising from monopolistic competition are zero at steady state.
} 
and the following demand functions: ${ }^{17}$

$$
g_{t}^{N}=\varphi_{g} g_{t} \text { and } g_{t}^{T}=\left(1-\varphi_{g}\right) g_{t}
$$

The government budget constraint is given by:

$$
p_{t}^{g} g_{t}=\tau-\frac{\left(i_{t-1}-1\right) b_{t-1}^{c}}{\pi_{t}}+s_{t} A_{t}^{*}+\left(b_{t}-\frac{b_{t-1}}{\pi_{t}}\right)-\left(d_{t}-\frac{d_{t-1}}{\pi_{t}}\right) .
$$

The government finances spending with taxes $\tau$, aid proceeds $s_{t} A_{t}^{*}$ (of which it is the direct recipient), changes in deposits held at the central bank $-\left(d_{t}-\frac{d_{t-1}}{\pi_{t}}\right)$, or domestic debt issuance $\left(b_{t}-\frac{b_{t-1}}{\pi_{t}}\right)$. It pays interest on government debt held by the private sector $b_{t}^{c}$, which is the difference between total debt and debt help by the central bank $b_{t}^{c b}$ :

$$
b_{t}=b_{t}^{c b}+b_{t}^{c} .
$$

We assume foreign aid $A_{t}^{*}$ follows the process:

$$
A_{t}^{*}=A^{*}+\rho_{A}\left(A_{t-1}^{*}-A^{*}\right)+A^{*} \epsilon_{t},
$$

where $A^{*}$ is the steady state level of aid and $\epsilon_{t}$ is an i.i.d. shock. Fiscal policy is determined by rules for deposits and gross debt. Deposits are determined as follows:

$$
d_{t}=\rho_{d} d_{t-1}+\left(1-\rho_{d}\right) d+(1-\gamma) s_{t}\left(A_{t}^{*}-A^{*}\right)
$$

where $d$ is a deposit target. When aid increases, the government initially spends a fraction $\gamma$. In this regard, $\gamma$ measures the degree of short term aid spending. Aid-related deposits are drawn down at rate $\rho_{d}$. Debt accumulation follows a simple rule:

$$
b_{t}-b_{t-1}=-\varsigma\left(b_{t-1}^{c}-b^{c}\right)
$$

where $\varsigma$ is small but positive. This ensures that open market operations-which affect government interest payments-do not influence the steady state fiscal position.

\section{The Central Bank}

We initially assume the economy is cashless, which implies the central bank balance sheet does not contain any monetary liabilities. Changes in its balance sheet are given by:

$$
b_{t}^{c b}-\frac{b_{t-1}^{c b}}{\pi_{t}}=\left(d_{t}-\frac{d_{t-1}}{\pi_{t}}\right)-s_{t}\left(R_{t}^{*}-R_{t-1}^{*}\right)
$$

\footnotetext{
${ }^{17}$ We have assumed for simplicity that the government demand for traded and non-traded goods is not sensitive to changes in the real exchange rate.
} 
where $R_{t}^{*}$ is the level of foreign reserves. Central bank policy is given by a Taylor rule:

$$
i_{t}=\frac{1}{\beta}\left(\pi_{t}^{N}\right)^{\phi_{\pi}}
$$

which implicitly defines the inflation objective $\pi^{N}=1$, and a reserve policy rule:

$$
R_{t}^{*}=\rho_{R} R_{t-1}^{*}+\left(1-\rho_{R}\right) R^{*}+(1-\omega)\left(A_{t}^{*}-A^{*}\right)
$$

where $R^{*}$ is a long-run target. ${ }^{18}$ The central bank initially accumulates a fraction $(1-\omega)$ of the increase in aid as reserves, which will eventually be drawn down at rate $\rho_{R}$. When the capital account is closed, $\omega$ is a direct measure of short term aid absorption.

\section{E. Equilibrium Conditions}

The labor market equilibrium (LL) is given by the following equation:

$$
l_{t}^{T}+l_{t}^{N}=\mathfrak{p} l_{t}^{a}+(1-\mathfrak{p}) l_{t}^{h} .
$$

Then there is the equilibrium in the non-traded goods market:

$$
y_{t}^{N}=c_{t}^{N}+g_{t}^{N}+\digamma\left(p_{t}^{N}, y_{t}^{N}, \pi_{i t}^{N}\right) .
$$

The balance of payments (bop) is derived by adding all budget constraints:

$$
A_{t}^{*}=\underbrace{\left[c_{t}^{T}+g_{t}^{T}-y_{t}^{T}+\mathfrak{p} Q\left(b_{t}^{a *}\right)-\left(i_{t-1}^{*}-1\right) b_{t-1}^{*}\right]}_{\text {current account deficit net of aid }}+\underbrace{\left(b_{t}^{*}-b_{t-1}^{*}\right)}_{\text {capital account surplus }}+\underbrace{\left(R_{t}^{*}-R_{t-1}^{*}\right)}_{\text {reserve accumulation }} .
$$

Equation (28) summarizes the possible uses of aid: it can finance a higher current account deficit (net of aid), a capital account surplus or an accumulation of reserves.

Finally, it is useful to introduce real gdp, which is defined as the sum of production in both sectors, valued at their normalized steady-state prices $p^{N}$ and $s$ :

$$
y_{t}=p^{N} y_{t}^{N}+s y_{t}^{T}
$$

We define an equilibrium in this economy as follows:

Definition: Given $\left\{b_{-1}, b_{-1}^{c}, b_{-1}^{*}, R_{-1}^{*}, d_{-1}^{g}\right\}$, the targets and policies $\left\{b^{c}, b^{a *}, R^{*}, d^{g}, \pi^{N}, \tau, \iota\right\}$, and the stochastic process for aid $\left\{A^{*}\right\}_{t=0}^{\infty}$, a symmetric equilibrium is a set of stochastic processes $\left\{c_{t}^{a}\right.$, $\left.c_{t}^{a N}, c_{t}^{a T}, c_{t}^{h}, c_{t}^{h N}, c_{t}^{h T}, l_{t}^{a}, l_{t}^{h}, l_{t}^{N}, l_{t}^{T}, y_{t}^{N}, y_{t}^{T}, g_{t}, g_{t}^{T}, g_{t}^{N}, b_{t}, b_{t}^{c}, b_{t}^{a c}, b_{t}^{c b}, b_{t}^{a *}, b_{t}^{*}, R_{t}^{*}, d_{t}^{g}\right\}_{t=0}^{\infty}$ and $\left\{w_{t}\right.$, $\left.s_{t}, p_{t}^{N}, p_{t}^{g}, \pi_{t}, \pi_{t}^{N}, i_{t}\right\}_{t=0}^{\infty}$ satisfying (i) the demand functions and price indices (2), (12), (16), and (17); (ii) the optimal conditions for consumers (5)-(7) and (8)-(9); (iii) the optimal conditions for firms (11), (13)-(15); (iv) the government rules and constraint (18)-(22); (v)the central bank rules and constraint (23)-(25); (vi) the aggregation and equilibrium market conditions for labor, non-traded goods and the bop (26)-(28).

\footnotetext{
${ }^{18}$ As an extension, we introduce a role for money and consider money growth rate rules.
} 


\section{F. The steady state}

We now briefly study the steady state of the model. We make a number of simplifying assumptions. First, we set all stock variables $\left(b^{c}, d^{g}, R^{*}, b^{*}\right)$ to zero. Second, we set:

$$
z^{N}=\delta^{1-\alpha}, \quad z^{T}=(1-\delta)^{1-\alpha} \text { and } \varkappa=\frac{\alpha}{\kappa_{c}} .
$$

where $\delta$ is the non-traded sector's share of employment and gdp, and $\kappa_{i}$ is the share of variable $i$ in gdp. These conditions ensure that $p^{N}, s, l$ and $y$ equal one. We also set $\iota=\frac{1}{\theta-1}$, to eliminate the distortion arising from monopolistic competition. Finally, non-traded equilibrium and the balance of payments —eqs (27) and (28)_impose the following constraints:

$$
\delta=\varphi \kappa_{c}+\varphi_{g} \kappa_{g} \quad \text { and } \quad 1-\delta=(1-\varphi) \kappa_{c}+\left(1-\varphi_{g}\right) \kappa_{g}-\kappa_{A} .
$$

For the remainder of the analysis, it will be useful to define two additional parameters:

$$
\xi=\frac{1-\varphi}{\varphi}>0 \quad \text { and } \quad \phi=\delta \xi-(1-\delta)=\kappa_{A}+\xi \kappa_{g}\left(\varphi_{g}-\left(1-\varphi_{g}\right) \frac{1}{\xi}\right)>0,
$$

$\xi$ measures home bias in consumption, and $\phi$ compares home bias in production relative to consumption. Note that $\phi$ is related to the share of aid and government spending on non-traded goods $\left(\varphi_{g}\right)$. Our focus is limited to the cases where $\phi>0$, which implies home bias in production is larger than home bias in consumption.

\section{G. The log-linearized version of the model}

A hat $(\hat{x})$ indicates log-deviations from steady state, except for stocks, for which it indicates changes in percent of steady state GDP. We first log-linearize the CPI index:

$$
\hat{p}_{t}^{N}=-\frac{1-\varphi}{\varphi} \hat{s}_{t}=-\xi \hat{s}_{t}
$$

to solve for $\hat{p}_{t}^{N}$. We will also replace employment with real gdp using the following formula:

$$
\hat{l}_{t}=\delta \hat{l}_{t}^{N}+(1-\delta) \hat{l}_{t}^{T}=\delta \frac{1}{\alpha} \hat{y}_{t}^{N}+(1-\delta) \frac{1}{\alpha} \hat{y}_{t}^{T}=\frac{1}{\alpha}\left(\delta \hat{y}_{t}^{N}+(1-\delta) \hat{y}_{t}^{T}\right)=\frac{1}{\alpha} \hat{y}_{t} .
$$

Consumers Adding eqs. (7) and (9) — in linearized form-yields the labor supply curve:

$$
\hat{y}_{t}=\frac{\alpha}{\psi}\left(\hat{w}_{t}-\hat{c}_{t}\right)
$$

Combining eqs. (5) and (6) generates a modified uncovered interest parity condition:

$$
\hat{i_{t}}=E_{t}\left(\hat{s}_{t+1}\right)-\hat{s}_{t}+\hat{\pi}_{t+1}-v_{b} \hat{b}_{t}^{*}
$$


where $v_{b}=\frac{v}{\mathfrak{p}}$. As in Gali et al (2007), the presence of non-asset holders results in a revised Euler equation that includes expected changes in real gdp as one of its determinants: ${ }^{19}$

$$
\hat{c}_{t}=E_{t}\left(\hat{c}_{t+1}\right)-\sigma\left(\hat{i}_{t}-\hat{\pi}_{t+1}\right)+\lambda\left[\hat{y}_{t}-E_{t}\left(\hat{y}_{t+1}\right)\right],
$$

where: $\sigma=\frac{\mathfrak{p}\left(\alpha+\kappa_{c} \psi\right)}{\Xi}, \lambda=\frac{(1-\mathfrak{p})(\psi+1) \alpha \psi}{\Xi}$, and $\Xi=\kappa_{c} \psi+\alpha-(1-\mathfrak{p}) \alpha(\psi+1)$.

Non-traded sector Log-linearizing eq. (13) produces the new-Keynesian Phillips curve:

$$
\hat{\pi}_{t}^{N}=\beta E_{t}\left(\hat{\pi}_{t+1}^{N}\right)-\frac{1}{\zeta} \hat{\mu}_{t}^{N},
$$

where $\hat{\mu}_{t}^{N}$ is the percentage change in markups in the non-traded sector:

$$
\hat{\mu}_{t}^{N}=-\left(\frac{1-\alpha}{\alpha}\right) \hat{y}_{t}^{N}-\hat{w}_{t}-\xi \hat{s}_{t},
$$

which implicitly defines the supply of non-traded goods (and labor demand in that sector).

Linearizing eq. (12) yields:

$$
\hat{\pi}_{t}^{N}=\hat{\pi}_{t}-\xi\left(\hat{s}_{t}-\hat{s}_{t-1}\right) .
$$

Traded sector The supply of traded goods (labor demand) is given by linearizing eq. (15):

$$
\hat{y}_{t}^{T}=-\frac{\alpha}{1-\alpha}\left(\hat{w}_{t}-\hat{s}_{t}\right) .
$$

The government Fiscal policy is summarized by the equation for total spending, the rule for government deposits and the process for aid: ${ }^{20}$

$$
\begin{gathered}
\kappa_{g} \hat{g}_{t}=\phi \hat{s}_{t}+\gamma \kappa_{A} \hat{A}_{t}^{*}+\left(1-\rho_{d}\right) \hat{d}_{t-1}-\left(\frac{1}{\beta}-1+\varsigma\right) \hat{b}_{t-1}^{c}, \\
\hat{d}_{t}=\rho_{d} \hat{d}_{t-1}+(1-\gamma) \kappa_{A} \hat{A}_{t}^{*}, \\
\hat{A}_{t}^{*}=\rho_{A} \hat{A}_{t-1}^{*}+\epsilon_{t} .
\end{gathered}
$$

The central bank Central bank policy is also summarized by three equations: the Taylor rule, reserve accumulation and its implications for government bonds outstanding:

$$
\begin{gathered}
\hat{i_{t}}=\phi_{\pi} \hat{\pi}_{t}^{N}, \\
\hat{R}_{t}^{*}=\rho_{R} \hat{R}_{t-1}^{*}+(1-\omega) \kappa_{A} \hat{A}_{t}^{*}, \\
\hat{b}_{t}=\left(\hat{R}_{t}^{*}-R_{t-1}^{*}\right)-\left(\hat{d}_{t}-\hat{d}_{t-1}\right)+(1-\varsigma) \hat{b}_{t-1}^{c} .
\end{gathered}
$$

\footnotetext{
${ }^{19}$ This equation is derived by combining the linearized version of eqs. (5), (8), and (9).

${ }^{20}$ The equation for government spending is derived by combining the linearized versions of eqs. (16), (18), (21), and (22).
} 
The labor market equilibrium Replacing labor demand in each sector and labor supply into eq. (26) yields the labor market equilibrium condition (LL):

$$
\hat{s}_{t}=-\vartheta_{w} \hat{w}_{t}+\vartheta_{c} \hat{c}_{t}-\vartheta_{\mu} \hat{\mu}_{t}^{N}
$$

where $\vartheta_{w}=\frac{1-\alpha+\psi}{\psi \phi}, \vartheta_{c}=\frac{1-\alpha}{\psi \phi}$, and $\vartheta_{\mu}=\frac{\delta}{\phi}$. The intuition behind equation (39) is as follows. When $\phi>0$, a real appreciation increases the aggregate demand for labor. Higher real wages — which increase labor supply and reduce labor demand - therefore require a real appreciation to clear the labor market. The same holds for higher markups - they decrease labor demand-while the opposite holds for higher consumption-it reduces labor supply. Note that the $\vartheta_{i} \mathrm{~s}$ are large since $\phi$ is close to zero.

We also derive the level of output consistent with the labor market equilibrium:

$$
\hat{y}_{t}=-\left(\frac{1-\alpha+\psi}{\alpha}\right)\left(\hat{c}_{t}+\phi \hat{s}_{t}+\delta \hat{\mu}_{t}^{N}\right) .
$$

Internal balance To generate the internal balance condition (IB), we insert demand for non-traded goods- $\left(\hat{c}_{t}^{N}=\hat{c}_{t}+(1-\varphi) \chi \hat{s}_{t}\right)$ and $\left(\hat{g}_{t}^{N}=\hat{g}_{t}\right)$-and supply into eq. (27): ${ }^{21}$

$$
\hat{s}_{t}=-\varepsilon_{w} \hat{w}_{t}-\varepsilon_{c} \hat{c}_{t}-\varepsilon_{A} \hat{A}_{t}^{*}-\varepsilon_{d} \hat{d}_{t-1}+\varepsilon_{b} \hat{b}_{t-1}^{c}-\varepsilon_{\mu} \hat{\mu}_{t}^{N}
$$

$$
\begin{gathered}
\text { where } \varepsilon_{w}=\varepsilon_{\mu}=\frac{\alpha \delta}{(1-\alpha) \Gamma}, \varepsilon_{c}=\frac{\varphi \kappa_{c}}{\Gamma}, \varepsilon_{A}=\frac{\gamma \varphi_{g} \kappa_{A}}{\Gamma}, \varepsilon_{d}=\frac{\varphi_{g}\left(1-\rho_{d}\right)}{\Gamma}, \varepsilon_{b}=\frac{\varphi_{g}}{\Gamma}\left(\frac{1}{\beta}-1+\varsigma\right) \\
\text { and } \Gamma=\underbrace{(1-\varphi) \kappa_{c} \chi}_{\text {private demand elasticity }}+\underbrace{\varphi_{g} \phi}_{\text {government demand elasticity }}+\underbrace{\delta \xi\left(\frac{\alpha}{1-\alpha}\right)}_{\text {supply elasticity }} .
\end{gathered}
$$

The intuition behind eq. (41) is straightforward. Higher consumption requires a real appreciation to reestablish internal balance: it reduce demand and, by lowering non-traded product wages, increases supply. The same holds for: higher aid, provided it is spent on non-traded goods $\left(\gamma>0\right.$ and $\left.\varphi_{g}>0\right)$; lagged government deposits, as they increase government resources; and higher wages and markups since they reduce supply. ${ }^{22}$ The magnitude of the adjustment depends negatively on the sum of demand and supply elasticities (see $\Gamma$ ).

We also derive a concentrated IB by solving eq. (39) for real wages and replacing in eq. (41):

$$
\hat{s}_{t}=-\mathcal{M}_{c} \hat{c}_{t}-\mathcal{M}_{A} \hat{A}^{*}{ }_{t}-\mathcal{M}_{d} \hat{d}_{t-1}+\mathcal{M}_{b} \hat{b}_{t-1}^{c}-\mathcal{M}_{\mu} \hat{\mu}_{t}^{N},
$$

where $\mathcal{M}_{c}=\left(\varphi \kappa_{c}+\delta \frac{\alpha}{1-\alpha+\psi}\right) \frac{1}{\Phi}, \mathcal{M}_{i}=\varepsilon_{i} \frac{\Gamma}{\Phi}$ for $i=(A, d, b), \mathcal{M}_{\mu}=\frac{\alpha \delta}{(1-\alpha) \Phi}\left(1-\frac{\delta \psi}{1-\alpha+\psi}\right)$, and $\Phi=\Gamma-\frac{\alpha \delta}{1-\alpha} \frac{\phi \psi}{1-\alpha+\psi}$.

\footnotetext{
${ }^{21}$ We use the equation for government spending to solve for $\hat{g}_{t}$.

${ }^{22}$ The opposite holds for lagged outstanding government debt $\hat{b}_{t-1}^{c}$.
} 
External balance Along the same lines we insert the demand for traded goods, $\hat{c}_{t}^{T}=\hat{c}_{t}-(1-\varphi) \chi \hat{s}_{t}$ and $\hat{g}_{t}^{T}=\hat{g}_{t}$; the supply; and eq. (37) into eq. (28):

$$
\hat{s}_{t}=\nu_{w} \hat{w}_{t}+\nu_{c} \hat{c}_{t}-\nu_{A} \hat{A}^{*}{ }_{t}-\nu_{R} \hat{R}_{t-1}^{*}+\nu_{b^{*}}\left(\hat{b}_{t}^{*}-\frac{1}{\beta} \hat{b}_{t-1}^{*}\right)+\nu_{d} \hat{d}_{t-1}-\nu_{b} \hat{b}_{t-1}^{c},
$$

where

$$
\begin{gathered}
\nu_{w}=\frac{\alpha(1-\delta)}{(1-\alpha) \Upsilon}, \nu_{c}=\frac{(1-\varphi) \kappa_{c}}{\Upsilon}, \nu_{A}=\frac{\kappa_{A}\left(\omega-\left(1-\varphi_{g}\right) \gamma\right)}{\Upsilon}, \nu_{R}=\frac{1-\rho_{R}}{\Upsilon}, \nu_{b^{*}}=\frac{1}{\Upsilon}, \\
\nu_{i}=\varepsilon_{i} \frac{\Gamma}{\Upsilon} \quad \text { for } \quad i=(d, b) \quad \text { and } \quad \Upsilon=(1-\varphi) \kappa_{c} \chi-\left(1-\varphi_{g}\right) \phi+\frac{\alpha(1-\delta)}{1-\alpha} .
\end{gathered}
$$

The intuition behind most terms in eq. (43) is the exact opposite of eq. (41). Regarding an increase in aid, external balance requires a real appreciation $\left(\nu_{A}>0\right)$ provided the aid is not fully accumulated as reserves $(\omega>0)$. On the other hand, if $\omega$ is close to zero or very low, higher aid may generate depreciation pressures if the resulting (hypothetical) increase in government spending is sufficiently tilted toward traded goods $\left(\varphi_{g}<1\right)$. Finally, we derive a concentrated EB equation as in eq. (42):

$$
\hat{s}_{t}=\mathcal{H}_{c} \hat{c}_{t}-\mathcal{H}_{A} \hat{A}^{*}-\mathcal{H}_{R} \hat{R}_{t-1}^{*}+\mathcal{H}_{b^{*}}\left(\hat{b}_{t}^{*}-\frac{1}{\beta} \hat{b}_{t-1}^{*}\right)+\mathcal{H}_{d} \hat{d}_{t-1}-\mathcal{H}_{b} \hat{b}_{t-1}^{c}-\mathcal{H}_{\mu} \hat{\mu}_{t-1}^{N},
$$

where $\mathcal{H}_{c}=\left((1-\varphi) \kappa_{c}+\delta \frac{\alpha}{1-\alpha+\psi}\right) \frac{1}{\Lambda}, \mathcal{H}_{i}=\nu_{i} \frac{\Upsilon}{\Lambda}$ for $i=\left(A, R^{*}, b^{*}, b, d\right), \mathcal{H}_{\mu}=\frac{\alpha(1-\delta)}{(1-\alpha) \Lambda} \frac{\delta \psi}{1-\alpha+\psi}$, and $\Lambda=\Upsilon-\frac{\alpha(1-\delta)}{1-\alpha} \frac{\phi \psi}{1-\alpha+\psi}$.

This concludes the presentation of the linearized version of the model. Note that, in its most general form, the model is summarized by a system of 13 equations $(30-41,43)$ and 13 unknowns: $\hat{c}_{t}, \hat{y}_{t}, \hat{s}_{t}, \hat{\pi}_{t}, \hat{\pi}_{t}^{N}, \hat{i}_{t}, \hat{b}_{t}^{*}, \hat{\mu}_{t}^{N}, \hat{w}_{t}, \hat{A}_{t}, \hat{d}_{t}^{g}, \hat{b}_{t}^{c}$, and $\hat{R}_{t}^{*}$. In the next section, we make a number of simplifying assumptions to reduce the analysis of the model to a system of either three or two equations.

\section{Fiscal and Reserve Policy Interaction under Flexible Prices}

We now study how the interaction of spending and reserve policy-a pair $(\gamma, \omega)$-affect the short run impact of aid under flexible prices $\left(\zeta=0, \hat{\mu}_{t}^{N}=0\right)$. We focus on the special case where $v_{b}=+\infty$, which closes the capital account $\left(\hat{b}_{t}^{*}=0\right)$, although we will later relax this restriction. We will use a $"(*)^{n}$ " superscript for equilibrium variables under flexible prices.

Given these assumptions, the short-run equilibrium of the model can be summarized by eqs. (39), (41) and (43), which we reproduce here for convenience:

$$
\begin{gathered}
\hat{s}_{t}^{n}=-\vartheta_{w} \hat{w}_{t}^{n}+\vartheta_{c} \hat{c}_{t}^{n}, \quad(L L) \\
\hat{s}_{t}^{n}=-\varepsilon_{w} \hat{w}_{t}^{n}-\varepsilon_{c} \hat{c}_{t}^{n}-\varepsilon_{A} \hat{A}_{t}^{*}-\varepsilon_{d} \hat{d}_{t-1}+\varepsilon_{b} \hat{b}_{t-1}^{c}, \quad(I B a) \\
\hat{s}_{t}^{n}=\nu_{w} \hat{w}_{t}^{n}+\nu_{c} \hat{c}_{t}-\nu_{A} \hat{A}^{*}{ }_{t}-\nu_{R} \hat{R}_{t-1}^{*}+\nu_{d} \hat{d}_{t-1}-\nu_{b} \hat{b}_{t-1}^{c} \quad(E B a)
\end{gathered}
$$


All three equations are represented in Figure (2). Given the range of parameter values we consider, $\vartheta_{w}>\varepsilon_{w}$, which implies the LL curve is steeper than the IBa curve. Policy responses to aid flows and lagged state variables $\left(\hat{d}_{t-1}, \hat{b}_{t-1}^{c}, \hat{R}_{t-1}^{*}\right)$ operate as exogenous shifters for IBa or EBa, while consumption is the latent variable that shifts all three curves endogenously. ${ }^{23}$

We can also use eqs. (42) and (44) to represent short run equilibrium:

$$
\begin{gathered}
\hat{s}_{t}^{n}=-\mathcal{M}_{c} \hat{c}_{t}^{n}-\mathcal{M}_{A} \hat{A}^{*}{ }_{t}-\mathcal{M}_{d} \hat{d}_{t-1}+\mathcal{M}_{b} \hat{b}_{t-1}^{c} \\
\hat{s}_{t}^{n}=\mathcal{H}_{c} \hat{c}_{t}^{n}-\mathcal{H}_{A} \hat{A}^{*}{ }_{t}-\mathcal{H}_{R} \hat{R}_{t-1}^{*}+\mathcal{H}_{d} \hat{d}_{t-1}-\mathcal{H}_{b} \hat{b}_{t-1}^{c}
\end{gathered}
$$

Both curves are represented in Figure (3). We will use Figure (2) to study the implication of aid increases for the labor market and Figure (3) to focus on private consumption.

We start our analysis with a version of the model where the government spends on non-traded goods exclusively $\left(\varphi_{g}=1\right)$, which simplifies the analysis, and then focus on the version where $\varphi_{g}<1$.

\section{A. Impact of Aid when $\varphi_{g}=1$}

When $\varphi_{g}=1$, the internal and external balance equations simplify as follows:

$$
\varepsilon_{A}=\frac{\gamma \kappa_{A}}{\Gamma}, \quad \mathcal{M}_{A}=\frac{\gamma \kappa_{A}}{\Phi}, \quad \nu_{A}=\frac{\omega \kappa_{A}}{\Upsilon}, \quad \mathcal{H}_{A}=\frac{\omega \kappa_{A}}{\Lambda} \quad \text { and } \quad \nu_{i}=\mathcal{H}_{i}=0 \quad \text { for } \quad i=(d, b) .
$$

In this case, the government's spending of the additional aid $(\gamma>0)$ affects internal balance only (the IB curves shift downward), while the central bank's sale of the aid-related FX $(\omega>0)$ affects external balance (the EB curves shift downward). We look at four policy combinations (see Figures (4) and (5)); point $a$ refers to steady state.

\section{Complete spending and absorption-point $b$}

If aid is spent and the central bank sells all the aid-related $\operatorname{FX}(\gamma=1, \omega=1)$, the short run equilibrium moves from point $a$ to $b$. The real exchange rate appreciates and consumption increases slightly. ${ }^{24}$ Real wages increase since the real appreciation increases labor demand and the increases in consumption reduces labor supply. ${ }^{25}$

\section{Complete spending but no absorption-point $c$}

If aid is spent but the central bank uses all of the FX to accumulate reserves $(\gamma=1, \omega=0)$, there is a-smaller-real appreciation and private consumption is crowded out. While the (smaller) real

\footnotetext{
${ }^{23}$ Note that participation in financial markets does not affect the flexible price equilibrium values for $\left(\hat{s}_{t}^{n}, \hat{w}_{t}^{n}, \hat{c}_{t}^{n}\right)$.

${ }^{24}$ The increase in consumption happens because $\nu_{A}>\varepsilon_{A}$, which reflects the fact that the private sector-being more intensive in the production of non-traded goods than in their consumption $(\phi>0)$ - benefits when relative demand for non-traded goods goes up.

${ }^{25}$ Note that the equilibrium is not given by the interaction of curves $I B a^{\prime}$ and $E B a^{\prime}$, as their position assumes consumption has not increased, in which case labor supply exceeds labor demand.
} 
appreciation still generates an increase in labor demand, the larger decrease in consumption increases labor supply and real wages decrease.

\section{Complete absorption but no spending_point $d$}

If the central bank sells the FX but government spending does not increase $(\gamma=0, \omega=1)$, there is a smaller real appreciation with higher consumption and real wages.

\section{No absorption and no spending-point $e$}

Finally, if aid is not spent but the FX is accumulated as reserves $(\gamma=0, \omega=0)$, there is no initial impact on the real exchange rate, consumption or real wages.

\section{B. Impact of Aid when $\varphi_{g}<1$}

When the government spends on traded goods, the fiscal policy response also affects the economy's external balance (Figure (6)). In the case of complete spending and absorption (point $b$ ), the resulting appreciation is smaller, since the shift in both curves is now smaller. In the case of spending without absorption, the IB curve shifts down and the EB curve shifts up ( $\left.E B a^{\prime \prime}\right)$, which also reduces the real appreciation (point $c$ ). Depending on the calibration, the latter policy may even result in a real depreciation, while the effect on consumption remains negative.

\section{Reserves Policy, the Real Exchange Rate and the Natural Rate of Interest}

Much of the policy debate about the short term response to aid takes spending as given and focuses on the central bank response; we will set $(\gamma=1)$ for the remainder of the paper and analyze the role of $\omega$.

It is helpful to derive the implications of aid on the natural rate of interest, which can be shown to follow the equation below:

$$
\hat{r}_{t}^{n}=-\mathfrak{n}_{A} \hat{A}^{*}{ }_{t}+\mathfrak{n}_{R}\left(\hat{R_{t}^{*}}-R_{t-1}^{*}\right)-\mathfrak{n}_{d}\left(\hat{d}_{t}-\hat{d_{t-1}}\right)-\mathfrak{n}_{b} b_{t-1}^{\hat{c}}
$$

with $\mathfrak{n}_{i}>0$ for all $i$ (see Appendix A for a derivation). The term $-\mathfrak{n}_{A}$ measures the impact of aid on the short term real interest rate when aid is both spent and absorbed and is close to zero. Interest rates will increase, however, if aid is not absorbed and reserves accumulate $\left(\hat{R}_{t}^{*}-R_{t-1}^{\hat{*}}\right) \uparrow$.

For a given increase in aid, Figure (7) displays the equilibrium pair $\left(\hat{r}_{t}^{n}, \hat{s}_{t}^{n}\right)$ as $\omega$ goes from one (complete absorption) to zero (no absorption). Our model generates a negative relationship between these variables: as reserve accumulation increases $(\omega \downarrow)$, the size of the real appreciation is reduced while the natural rate of interest increases - consistent with the crowding out of the private sector. In addition, as the share of spending on traded goods increases $\left(\varphi_{g} \downarrow\right)$, the range of real exchange rate movements shifts up - there is less appreciation — while the range of real interest rates remains the same.

To summarize, the experiments presented here have shown that, when capital mobility is limited, the short run impact of aid on the real exchange rate and other real variables depends crucially on the 
combination of fiscal and reserve policy responses, as well as the composition of spending. The differences become starker once we introduce nominal rigidities, which we discuss in the next section.

\section{Policy Interactions under Sticky Prices}

We now analyze how nominal rigidities $(\zeta>0)$ affect the short-run effects of aid. It is no longer possible to fully characterize the short run equilibrium with the ( $L L, I B a, E B a)$ system, although we will use it to clarify the role of nominal rigidities. Instead, we simulate the model calibrated after calibrating it to the Ugandan economy.

\section{A. Calibration}

The calibration is shown in Table (2). $\beta$ is set so the equilibrium annual real interest rate is 4 percent. The choice of $\delta, \kappa_{g}$ and $\kappa_{A}$ is based on Uganda's national income and fiscal accounts prior to the aid surge. ${ }^{26}$ We set $\varphi_{g}=0.8$ based on data from the Bank of Uganda; $\kappa_{c}$ and $\varphi$ follow from the country's resource constraints. ${ }^{27}$ Our baseline maintains $v_{b}=+\infty$.

The labor share $\alpha$ is calibrated to the employment compensation share in Uganda's 2002 input-output table, and $\chi$ is calibrated to the estimate of import demand elasticity for Uganda from Tokarick (2009). We do not have estimates on labor supply elasticity $\left(\psi^{-1}\right)$; we set $\psi=2$. We set $\zeta=$ 10 , which is consistent with firms changing prices every 3.5 quarters.

The share of asset holders $\mathfrak{p}$ is set to 40 percent, based on a comprehensive survey of financial access in Uganda. ${ }^{28}$ The coefficient $\rho_{A}$ is chosen so that the increase in aid has a half life of about a year and half; the choice of $\rho_{R}$ ensures reserve accumulation is persistent. Finally, Uganda, like many African countries, does not set operational targets on interest rates; we choose a Taylor rule for simplicity and our value for $\phi_{\pi}(1.5)$ is standard. We experiment with alternative monetary policy rules below.

\footnotetext{
${ }^{26}$ NIA data is available at http://www.ubos.org/. Fiscal accounts data was compiled from IMF staff reports, available at http://www.imf.org/external/country/UGA/index.htm.

${ }^{27}$ The Bank of Uganda compiles data on direct imports of goods and services by the general government financed with aid — both budget support and project aid. This statistic (16 percent of total government spending in 1999) provides a lower bound on total government spending on traded goods. We thank Kenneth Egesa for providing us with this data.

${ }^{28}$ The survey, titled "Financial Access Survey for Financial Sector Deepening" (2009), was conducted by the Steadman group; it surveyed 3000 Ugandans and covered access to both the formal and informal financial sector. Information available at http://www.finscope.co.za/uganda.html.
} 


\section{B. Simulation Results}

We examine the dynamics of the model following a 50 percent increase in $A_{t}^{*}$ (about 3 percentage points of GDP), similar to what Uganda experienced during the aid surge. Impulse response functions are computed under both sticky and flexible prices. ${ }^{29}$

\section{Complete spending and absorption (Figure 8)}

In this case, there is an equivalent increase in government spending and the current account deficit (net of aid). ${ }^{30}$ The real exchange rate appreciates and the impact on real GDP is close to zero: the expansion of the non-traded sector is almost fully offset by the contraction in the traded sector. Real wages increase. There is a small increase in non-traded inflation (shown in annualized terms), which is consistent with a small decline in markups. Headline inflation falls while nominal and real interest rates remain unchanged. Note that the simulation under sticky prices is very similar to its flexible price counterpart.

\section{Complete spending, zero absorption (Figure 9)}

This case matches the policy response observed in Uganda (Table 1). Government spending increases but the current account deficit net of aid stays flat. The real exchange rate now displays a depreciation, there is a large decline in markups, and inflation increases considerably. The monetary policy response results in a large increase in real interest rates, while output expands for two reasons: an increase in labor supply_-related to the crowding out of consumption-and higher demand pressures. Note that the performance of the model with sticky prices is very different than the flexible-price version: we observe higher output and inflation, lower markups, higher real wages and a more depreciated real exchange rate.

\section{Discussion}

The simulations raise two related questions: why are there demand pressures when aid is spent but not absorbed, and how can these pressures generate a temporary real depreciation?

\section{Why are demand pressures larger when aid is spent but not absorbed?}

To understand this question, it is helpful to look at one-sector closed economy new-Keynesian models. These models typically feature three equations: an IS curve that relates the output gap to the difference between the actual real interest rate and the natural rate of interest; a new-Keynesian Phillips; and a monetary policy rule. ${ }^{31}$ It is a well known property of these models that real shocks

\footnotetext{
${ }^{29}$ While the aid surge in Uganda lasted four years, our focus is mainly on the first year. Since most of the features in our model that can generate a real depreciation are related to the presence of nominal rigidities, and there are few real rigidities, we cannot generate a persistent real depreciation that lasts beyond the first few quarters. We leave an examination of real rigidities for future work.

${ }^{30}$ The log-linearized current account deficit net of aid (in percent of GDP) is given by: $\hat{c} a_{t}=\kappa_{A}\left((1+\phi) \hat{s}_{t}+\hat{A}_{t}^{*}-\hat{y}_{t}\right)-\hat{R}_{t}^{*}-R_{t-1}^{\hat{*}}$.

${ }^{31}$ See Gali (2008).
} 
affect inflation through their implication for $\hat{r}_{t}^{n}$. In particular, increases in $\hat{r}_{t}^{n}$ will generate a positive output gap, provided monetary policy is not optimal, which is our case since $\phi_{\pi}<<\infty$.

When the capital account is closed, our model admits the same representation after some additional derivation, i.e., it is isomorphous to the closed economy model. ${ }^{32}$ So the same logic applies here: since not absorbing the aid raises $\hat{r}_{t}^{n}$, it generates demand pressures.

\section{How can demand pressures generate a temporary real depreciation?}

We return to equations (39), (41) and (43), which are represented in Figure (10). Since these three equations now feature four endogenous variables $\left(\hat{s}_{t}, \hat{w}_{t}, \hat{c}_{t}, \hat{\mu}_{t}^{N}\right)$, they are not sufficient to summarize the short-run equilibrium. However, we can use this system to show how the first three variables $\left(\hat{s}_{t}, \hat{w}_{t}, \hat{c}_{t}\right)$ change as non-traded markups decrease-a sufficient indicator of demand pressures.

When $\hat{\mu}_{t}^{N}=0$, the short term equilibrium is the same as under flexible prices (point $c$ ). Starting from this point, a decline in markups shifts the $I B a$ curve up-since it reduces pressures on the real exchange rate to appreciate to reestablish internal balance-and shifts the $L M$ curve up — since it results in an increase in aggregate labor demand. As a result, lower markups result in a relatively more depreciated real exchange rate and higher real wages. The decline in consumption is also slightly smaller. All possible equilibria-which depend on $\hat{\mu}_{t}^{N}$ —are represented on the $S S$ line. Note that, for the real exchange rate to depreciate in absolute terms, it must be the case that real wages increase beyond $w^{\prime \prime}$. The point $c^{\prime}$ represents the short-term equilibrium from the benchmark.

Intuitively, the (relative) real depreciation can be understood by focusing on external balance. Since higher real wages tend to reduce the supply of traded goods - relative to the flexible price case - a more depreciated real exchange rate will reestablish external balance by increasing product wages in the sector and switching expenditure away from traded goods.

In sum, we have shown that, in addition to the flexible-price effects described earlier, spending but not absorbing the aid generates demand pressures and results in a relatively more depreciated exchange rate. In light of this discussion, it is helpful to decompose movements in macroeconomic variables into the component that is due to the flexible-price specification of the model and the additional movement that results from nominal rigidities and demand pressures. In the case of the real exchange, and provided the capital account is closed, one can use eqs. (42) and (44) for this purpose, which yields the following result:

$$
\hat{s}_{t}=\hat{s}_{t}^{n}-\mathfrak{d}_{\mu} \hat{\mu}_{t}^{N}
$$

where:

$$
\mathfrak{d}_{\mu}=\frac{\mathcal{M}_{c} \mathcal{H}_{\mu}+\mathcal{H}_{c} \mathcal{M}_{\mu}}{\mathcal{M}_{c}+\mathcal{H}_{c}}
$$

Equation (46) clarifies what makes a real depreciation more likely when aid is spent and not absorbed: factors that decrease the natural appreciation of the real exchange rate $\left(\hat{s}_{t}^{n}\right)$ and factors that amplify demand pressures-the decline in $\hat{\mu}_{t}^{N}$.

\footnotetext{
${ }^{32}$ This additional derivation is available upon request.
} 


\section{Sensitivity Analysis}

We now analyze how several features of the model affect the impact of aid and how these effects vary with the reserve policy response. Table 3 compares results from the benchmark case with six variations: (i) government spending on non-traded goods only; (ii) excluding non-asset holder consumers; (iii) imperfect substitutability of labor; (iv) smaller aid persistence; (v) alternative preferences; and (vi) a perfectly open capital account. For the first five cases, we limit our discussion to four variables: the real exchange rate and output, both measured as average deviations over the year; accumulated inflation over the same period and the real interest rate $\left(\hat{r}_{t}-\hat{\pi}_{t+1}\right)$.

\section{Government spending on non-traded goods only}

When $\varphi_{g}$ goes from eighty percent to one hundred, the economy experiences a more appreciated real exchange rate, even though there is still a small depreciation when there is no absorption. Consistent with the previous discussion, this is due to changes in the natural real exchange rate $\hat{s}_{t}^{n}$ (not shown) rather than smaller demand pressures.

\section{Excluding Non-Asset Holders}

When the share of non-asset holders falls from sixty percent to zero, the response of the economy varies depending on whether aid is absorbed or not. In the former case results are similar to the benchmark. In the latter, demand pressures are smaller and the real exchange rate appreciates, which highlights the fact that non-asset holders amplify demand pressures.

\section{Imperfect labor substitutability}

We experiment with labor supplied to different sectors being imperfectly substitutable:

$$
l_{t}=\left[\delta^{-\frac{1}{\varrho}}\left(l_{t}^{N}\right)^{\frac{1+\varrho}{\varrho}}+(1-\delta)^{-\frac{1}{\varrho}}\left(l_{t}^{T}\right)^{\frac{1+\varrho}{\varrho}}\right]^{\frac{\varrho}{1+\varrho}},
$$

which allows for wage differentials across sectors and results in sector specific labor supply conditions: $\hat{l}_{t}^{i}=\varrho\left(\hat{w}_{t}^{i}-\hat{w}_{t}\right)+\hat{l}_{t}$ for $i=(T, N) .{ }^{33}$ We set $\varrho=2$. In this case, aid results in a more appreciated real exchange rate regardless of whether reserves increase or not. This result reflects a more appreciated flexible-price real exchange rate $\left(\hat{s}_{t}^{n}\right.$, not shown).

\section{Lower persistence of aid}

We now analyze what happens when $\rho_{A}$ goes from 0.87 to 0.6 . We raise the size of the initial shock so the increase over the first year is the same as in the benchmark. In the case of complete absorption, the increase in aid generates a smaller real appreciation and the impact on inflation and output is slightly higher. When aid is not absorbed, the economy experiences a larger real depreciation and output and inflation increase significantly.

These results can be explained as follows: the larger size of the shock and the smaller persistence imply most of the aid increase takes place when nominal rigidities matter, while the negative impact on consumption is smaller.

\footnotetext{
${ }^{33}$ This follows the specification in Bouakez, and others (2005).
} 


\section{Alternative preferences}

The preferences we have used so far have one important drawback: shocks with negative wealth effects tend to be expansionary through the effect of consumption on labor supply. This explains why spending but not absorbing the aid leads to an expansion in output when prices are flexible. ${ }^{34}$ To assess robustness, we explore an alternative specification for utility, based on Greenwood, Hercowitz and Huffman (1989): $u\left(c_{t}, l_{t}\right)=\log \left(c_{t}-\frac{\varkappa}{1+\psi}\left(l_{t}\right)^{1+\psi}\right)$. In this case labor supply depends on real wages only: $\hat{l}_{t}=\frac{1}{\psi} \hat{w}_{t} \cdot{ }^{35}$ For simplicity, we will assume there are only asset holders $(\mathfrak{p}=1)$.

Table 3 summarizes the results from this specification, under both flexible and sticky prices. Under flexible prices, results are similar, the main exception being the response of output when aid is spent but not absorbed, which is now approximately zero. On the other hand, when prices are sticky, spending but not absorbing the aid generates larger demand pressures and an even larger real depreciation, which indicates the key results are robust to this specification.

\section{Opening the capital account}

We now assume the capital account is open and set $v_{b}=0.0125$, which implies that, ceteris paribus, a decrease in private NFA by 5 percent of annual GDP leads to an increase in annualized domestic interest rates of 100 basis points. In addition to $\left(\hat{s}_{t}, \hat{y}_{t}, \hat{\pi}_{t}, \hat{r}_{t}-\hat{\pi}_{t+1}\right)$ we also study the impact on the the bop categories (see Table 3).

In this case, reserve accumulation has a smaller impact on real variables, including the current account deficit which is now determined in part by inter-temporal considerations. When all aid-related foreign exchange is sold to the private sector, there is both a higher current account deficit net of aid and a capital account surplus. Since absorption is now smaller, real exchange rate pressures are smaller. When the central bank accumulates reserves, the private sector borrows from the rest of the world to maintain a broadly similar-although smaller-current account deficit, resulting in large capital inflows.

Relative to the previous discussion, the sterilized accumulation of reserves-during an aid-financed fiscal expansion-cannot generate a short-term real depreciation. Note however that an unsterilized reserve accumulation will lead to a real depreciation, regardless of the degree of capital mobility. We discuss the role of monetary policy in the next section.

\section{E. The Role of Monetary Policy}

One of the weaknesses of the benchmark results was that the real depreciation was associated with an increase in inflation, which is at odds with the evidence (see Table 1). We conclude our paper with an analysis of alternative monetary policy responses, with a focus on the behavior of inflation. We

\footnotetext{
${ }^{34}$ This expansionary effect has long been recognized as a weakness in the emerging markets literature. See, among others, Chari, Kehoe, and McGrattan (2005) Kehoe and Rull (2009).

${ }^{35}$ See Monacelli and Perotti (2008) for an application of a more general specification-which encompasses both specifications used here-to the modeling of fiscal policy. See also Burstein, Eichenbaum, and Rebelo (2007) for an application to episodes of large nominal devaluations.
} 
compare the benchmark with: (i) headline inflation targeting; (ii) incomplete reserve sterilization; and (iii) inflation targeting implemented via operational targets on money growth (Table 4).

\section{Headline inflation targeting}

Our choice of target draws on the literature on monetary policy in models with varying degrees of nominal rigidities across sector: authorities should target the inflation of goods with sticky prices since it summarizes the distortions stemming from nominal rigidities. ${ }^{36}$

In practice, authorities typically target headline inflation. If this is the case, a policy of spending and absorb results in a loosening of monetary policy: there is higher non-traded inflation, a smaller real appreciation and an expansion in output. On the other hand, since headline and non-traded inflation behave similarly when aid is not absorbed, headline inflation targeting does not differ from the benchmark.

\section{Incomplete Reserve Sterilization}

As discussed in Berg, and others (2007), in contrast with Uganda, some of the countries that accumulated reserves during scaling-up episodes did not fully sterilize. To analyze such scenario, we introduce real money balances in the representative agent's utility function, which leads to a standard money demand equation (see Appendix B for a derivation):

$$
\hat{m}_{t}=\hat{c}_{t}-\mathfrak{y} \hat{i_{t}}
$$

where $\hat{m}_{t}$ is the percent deviation of real money balances from their steady state value and $\mathfrak{y}$ is the aggregate interest semi-elasticity of money demand. ${ }^{37}$ The central bank balance sheet now incorporates money:

$$
\hat{b_{t}^{c}}-(1-\varsigma) b_{t-1}^{\hat{c}}=-\kappa_{m}\left(\hat{m}_{t}-\hat{m}_{t-1}+\hat{\pi}_{t}\right)+\left(\hat{R}_{t}^{*}-R_{t-1}^{\hat{*}}\right)-\left(\hat{d}_{t}^{g}-d_{t-1}^{\hat{g}}\right) .
$$

An increase in reserves need not lead to an increase in government bonds outstanding but can be financed instead with an increase in the money stock. Such lack of sterilization would result in a loosening of policy, which suggests the following variant of the Taylor rule:

$$
\hat{r}_{t}=\phi_{\pi} \hat{\pi}_{t}^{N}-\frac{1-\mathfrak{f}}{\kappa_{m} \mathfrak{y}}\left(\hat{R}_{t}^{*}-R_{t-1}^{\hat{*}}\right)
$$

where $\mathfrak{f}$ measures sterilization, with the impact of incomplete sterilization $(\mathfrak{f}<1)$ depending on $\kappa_{m}$ and $\mathfrak{y}$ (see appendix B for derivation). The parameter $\left(\kappa_{m}\right)$ is calibrated to the share of base money in Uganda and the choice of $\mathfrak{y}$ is based on an OLS regression of nominal money balances on nominal interest rates and nominal output. We choose $\mathfrak{f}=0.9$.

When sterilization is incomplete reserve accumulation results, not surprisingly, in a large depreciation of the real exchange rate, a large increase in output and a spike in inflation.

\footnotetext{
${ }^{36}$ See Gali and Monacelli (2005), Erceg, Henderson, and Levin (2003), Aoki (2001), among others.

${ }^{37}$ The utility derived from holding real money balances does not enter separately, which implies the linearized Euler equation also depends on linearized real money balances. It can be shown that, since the share of real money balances is very small, these complications can be safely ignored. See McCallum (2001).
} 


\section{Money targeting}

De jure, most African countries implement monetary policy by setting operational targets on monetary aggregates. ${ }^{38}$ We therefore replace equation (24) with the following rule:

$$
\frac{M_{t}}{M_{t-1}}=\pi_{t}^{-\phi_{\pi}^{m}}
$$

which implies the following rule for interest rates:

$$
\hat{i_{t}}=\frac{1+\phi_{\pi}^{m}}{\mathfrak{y}} \hat{\pi}_{t}+\frac{1}{\mathfrak{y}}\left(\hat{c}_{t}-\hat{c}_{t-1}\right)+\hat{i}_{t-1}
$$

The resulting rule differs from the standard Taylor rule in three ways: interest rates increase when consumption growth increases, the lagged short term interest rate enters with coefficient one, and the weight on inflation depends on $\phi_{\pi}^{m}$ and $\mathfrak{y}$. We assume $\phi_{\pi}^{m}$ is such that the coefficient on inflation is equal to $\phi_{\pi}$.

Table 6 summarizes the results of the model under money targeting. Relative to the benchmark, results are similar when aid is fully absorbed. When aid is not absorbed, money targeting results in a somewhat similar result for the exchange rate and output. However, the impact on inflation is much smaller. This is due to the fact that inflation remains well anchored by the presence of the lagged interest rate in the policy rule. ${ }^{39}$

\section{Conclusion}

We have focused on the macroeconomic implications of different responses to aid surges. In particular, and following recent episodes of aid surges in low income countries, we emphasize the interaction of fiscal policy and reserve management. We find that this interaction matters for the short-run effects of aid.

When calibrated to Uganda, the model is able to capture some of the main features of the aid inflow episode, notably the response of the real exchange rate and the real interest rate. However, our assessment of the model has been limited to the qualitative response of key variables. We are currently working on a companion paper where we assess whether an extended version of this model - with investment, real rigidities, uncertainty and terms of trade shocks — can reproduce the quantitative path of the Ugandan economy during the scaling-up period. In a separate paper, we are also working on the welfare implications of various fiscal and reserve policy response to aid, using the same framework presented here.

Our analysis has focused on the short term. The interaction of reserve and fiscal policy also has implications for the medium-term effects of aid, since the (potentially) positive effects from higher

\footnotetext{
${ }^{38}$ See IMF (2008b), Chapter 2 of Spring 2008 REO.

${ }^{39}$ This result does not imply money targeting is superior to an interest rate rule. The anchoring role of lagged interest rate is not specific to money targeting but is instead a general property of optimal rules (see Woodford 1999). In addition, money targeting is subject to the (well-known) instability and volatility of money demand. See Berg, Portillo, and Unsal (2010) for a comparative analysis of money and interest rate rules in low-income countries.
} 
aid-financed public investment can be offset by the crowding out of private investment induced by reserve accumulation. The analysis is further complicated by Dutch-Disease type effects. We address these issues in a separate paper (Berg, and others (2010)).

Finally, we believe our approach is applicable to issues besides aid. The macroeconomics of natural resource booms in low-income countries are closely related to that of aid surges. ${ }^{40}$ More broadly, the fiscal-monetary-policy interactions involved here are of general importance in low-income countries. For example, a spend-and-absorb response resembles a domestically-financed fiscal expansion, combined with a sterilized intervention (financed by the aid). We leave an in-depth discussion of sterilized interventions for future work.

${ }^{40}$ See Dagher, and others (2010) for an application of a closely-related model to the expected oil windfall in Ghana. 


\section{APPENDICES}

\section{A. Appendix A : The flexible price solution when the capital account is closed}

We combine equations (42) and (44) to solve for the flexible-price policy rule for consumption:

$$
\hat{c}_{t}^{n}=\underbrace{\frac{\kappa_{A}\left(\Lambda^{-1}-\Phi^{-1}\right)}{\mathcal{M}_{c}+\mathcal{V}_{c}}}_{\mathfrak{u}_{A}} \hat{A}_{t}^{*}+\underbrace{\frac{\Phi^{-1}}{\mathcal{M}_{c}+\mathcal{H}_{c}}}_{\mathfrak{u}_{d}}\left(\hat{d}_{t}-\hat{d}_{t-1}\right)-\underbrace{\frac{\Lambda^{-1}}{\mathcal{M}_{c}+\mathcal{H}_{c}}}_{\mathfrak{u}_{R}}\left(\hat{R}_{t}^{*}-\hat{R}_{t-1}^{*}\right)+\underbrace{\frac{\mathcal{M}_{b}}{\mathcal{M}_{c}+\mathcal{H}_{c}}}_{\mathfrak{u}_{b}} \hat{b}_{t-1}^{c} .
$$

Reinserting equation (50) into equation (44) yields the policy rule for the flexible price real exchange rate:

$$
\hat{s}_{t}^{n}=-\underbrace{\frac{\kappa_{A}\left(\mathcal{H}_{c} \Lambda^{-1}+\mathcal{M}_{c} \Phi^{-1}\right)}{\mathcal{H}_{c}+\mathcal{M}_{c}}}_{\mathfrak{d}_{A}} \hat{A}_{t}^{*}+\underbrace{\mathcal{H}_{c} \mathfrak{u}_{d}}_{\mathfrak{d}_{d}}\left(\hat{d}_{t}-\hat{d}_{t-1}\right)+\underbrace{\mathcal{M}_{c} \mathfrak{u}_{R}}_{\mathfrak{d}_{R}}\left(\hat{R}_{t}^{*}-\hat{R}_{t-1}^{*}\right)+\underbrace{\mathcal{H}_{c} \mathfrak{u}_{b}}_{\mathfrak{d}_{b}} \hat{b}_{t-1}^{c} .
$$

Inserting equations (50) and (51) into equation (40), imposing that $\hat{\mu}_{t}^{N}=0$ and rearranging terms yields the policy rule for the natural rate of output:

$\hat{y}_{t}^{n}=-\underbrace{\frac{\alpha\left(\mathfrak{u}_{A}-\phi \mathfrak{d}_{A}\right)}{1-\alpha+\psi}}_{\mathfrak{m}_{A}} \hat{A}^{*}-\underbrace{\frac{\alpha\left(\mathfrak{u}_{d}+\phi \mathfrak{d}_{d}\right)}{1-\alpha+\psi}}_{\mathfrak{m}_{d}}\left(\hat{d}_{t}-\hat{d}_{t-1}\right)+\underbrace{\frac{\alpha\left(\mathfrak{u}_{R}-\phi \mathfrak{d}_{R}\right)}{1-\alpha+\psi}}_{\mathfrak{m}_{R}}\left(\hat{R}_{t}^{*}-\hat{R}_{t-1}^{*}\right)-\underbrace{\frac{\alpha\left(\mathfrak{u}_{b}+\phi \mathfrak{d}_{b}\right)}{1-\alpha+\psi}}_{\mathfrak{m}_{b}} \hat{b}_{t-1}^{c}$.

Finally, we insert equations (51) and (52) in the Euler equation (31) which, after using equations (34), (37) and (35) to solve for expected future state variables, yields the expression for the natural rate in (45) where:

$$
\begin{gathered}
\mathfrak{n}_{A}=\frac{1-\rho_{A}}{\sigma}\left[\left(\mathfrak{u}_{A}+\mathfrak{m}_{A} \lambda\right)+(1-\gamma)\left(\mathfrak{u}_{d}+\mathfrak{m}_{d} \lambda\right) \kappa_{A}-(1-\omega)\left(\mathfrak{u}_{R}+\mathfrak{m}_{R} \lambda\right) \kappa_{A}\right], \\
\mathfrak{n}_{d}=\frac{1-\rho_{d}}{\sigma}\left(\mathfrak{u}_{d}+\mathfrak{m}_{d} \lambda\right)+\frac{1}{\sigma}\left(\mathfrak{u}_{b}+\mathfrak{m}_{b} \lambda\right), \quad \mathfrak{n}_{R}=\frac{1-\rho_{R}}{\sigma}\left(\mathfrak{u}_{R}+\mathfrak{m}_{R} \lambda\right)+\frac{1}{\sigma}\left(\mathfrak{u}_{b}+\mathfrak{m}_{b} \lambda\right), \quad \text { and } \\
\mathfrak{n}_{b}=\frac{\varsigma}{\sigma}\left(\mathfrak{u}_{b}+\mathfrak{m}_{b} \lambda\right) .
\end{gathered}
$$

\section{B. Appendix B : Introducing money in the utility function}

The utility function in equation (3) is replaced with the following specification:

$$
u\left(c_{t}^{a}, \frac{M_{t}^{a}}{P_{t}}, l_{t}^{a}\right)=\log \left\{\left[\mathfrak{z}^{a}\left(c_{t}^{a}\right)^{\frac{\eta-1}{\eta}}+\left(1-\mathfrak{z}^{a}\right)\left(\frac{M_{t}^{a}}{P_{t}}\right)^{\frac{\eta-1}{\eta}}\right]^{\frac{\eta}{1-\eta}}\right\}-\frac{\varkappa}{1+\psi}\left(l_{t}^{a}\right)^{1+\psi}
$$

The non-asset holders' utility function is the same as in (53), except that $\mathfrak{z}^{a} \neq \mathfrak{z}^{h}$. The budget constraints for the two types of households now include real money balances $\left(m_{t}^{i}=\frac{M_{t}^{i}}{P_{t}}\right)$ :

$$
c_{t}^{a}+b_{t}^{a c}+s_{t} b_{t}^{a *}=w_{t}^{N} l_{t}^{a N}+w_{t}^{T} l_{t}^{a T}+i_{t-1} \frac{b_{t-1}^{a c}}{\pi_{t}}+m_{t}^{a}-\frac{m_{t-1}^{a}}{\pi_{t}}+s_{t} i_{t-1}^{*} b_{t-1}^{a *}-s_{t} Q\left(b_{t}^{a *}\right)+\Omega_{t}^{N}-\tau^{a}+\varpi^{a}
$$




$$
c_{t}^{h}=w_{t} l_{t}^{h}-\tau^{h}-\varpi^{a}+m_{t}^{h}-\frac{m_{t-1}^{h}}{\pi_{t}}
$$

First order conditions with respect to $m_{t}^{i}$ yield the following money demand equations:

$$
\begin{gathered}
m_{t}^{a}=\left(\frac{1-\mathfrak{z}^{a}}{\mathfrak{z}^{a}}\right)^{\eta} c_{t}^{a}\left(\frac{i_{t}-1}{i_{t}}\right)^{-\eta} \\
m_{t}^{h}=\left(\frac{1-\mathfrak{z}^{h}}{\mathfrak{z}^{h}}\right)^{\eta} c_{t}^{h}
\end{gathered}
$$

$\mathfrak{p}^{a}$ and $\mathfrak{p}^{h}$ are chosen so $\frac{m^{a}}{c^{a}}=\frac{m^{h}}{c^{h}}=\frac{m}{c}=\frac{\kappa_{m}}{\kappa_{c}} \cdot{ }^{41}$ Adding the log-linear versions of equations (56) and (57) yields the following aggregate demand equation:

$$
\hat{m}_{t}=\hat{c}_{t}-\mathfrak{y} \hat{\imath}_{t}
$$

where $\mathfrak{y}=\mathfrak{p} \eta \frac{\beta}{1-\beta}$. This is eq. (47) in the text. The Euler equation is revised to account for the impact of inflation on non-asset holder's income:

$$
\hat{c}_{t}=E_{t}\left(\hat{c}_{t+1}\right)-\sigma\left(\hat{i}_{t}-\hat{\pi}_{t+1}\right)+\lambda\left[\hat{y}_{t}-E_{t}\left(\hat{y}_{t+1}\right)\right]-\theta_{m}\left[\hat{t}_{t}-E_{t}\left(\hat{t}_{t+1}\right),\right.
$$

where $\hat{t}=\hat{m}_{t}-\hat{m}_{t-1}+\pi_{t}$ and $\theta_{m}=(1-\mathfrak{p}) \kappa_{m} \alpha \psi \Xi^{-1}$. We have assumed for simplicity that transfers adjust so that the non-asset holders' inflation tax depends on aggregate money balances. As steady state real money balances are positive these central bank liabilities are backed by government debt $b^{c b}$, which implies there is now an inflation tax that accrues to the government. The demand for non-traded goods thus depends positively on $\hat{\pi}_{t}$, which implies the IBa equation features an additional term $-\varepsilon_{\pi} \hat{\pi}_{t}$ where:

$$
\varepsilon_{\pi}=\frac{\kappa_{m}}{\Gamma}
$$

We conclude by deriving a variant of the Taylor rule with incomplete sterilization. We start by using eqs. (48) and (58)to derive the rule for open market operations that is consistent with the simple Taylor rule:

$$
\hat{b_{t}^{c}}-(1-\varsigma) \hat{b_{t-1}^{c}}=-\kappa_{m}\left(\hat{c}_{t}-\mathfrak{y} \phi_{\pi} \hat{\pi}_{t}^{N}-\hat{m}_{t-1}+\hat{\pi}_{t}\right)+\left(\hat{R}_{t}^{*}-R_{t-1}^{*}\right)
$$

Following a Taylor rule implies reserve accumulation needs to be fully sterilized. We therefore modify equation (61) as follows:

$$
\hat{b_{t}^{c}}-(1-\varsigma) \hat{b_{t-1}^{c}}=-\kappa_{m}\left(\hat{c}_{t}-\mathfrak{y} \phi_{\pi} \hat{\pi}_{t}^{N}-\hat{m}_{t-1}+\hat{\pi}_{t}\right)+\mathfrak{f}\left(\hat{R}_{t}^{*}-R_{t-1}^{*}\right),
$$

where $\mathfrak{f}$ measures the degree of sterilization $(0 \leq \mathfrak{f} \leq 1)$. Using equations (48) and (62) to solve for the nominal interest rate yields the policy rule in equation (49).

\footnotetext{
${ }^{41}$ Unlike the benchmark case, we assume that non-asset holders maximize instantaneous utility rather than lifetime utility. This simplifies their money demand equation without qualitatively affecting the results.
} 


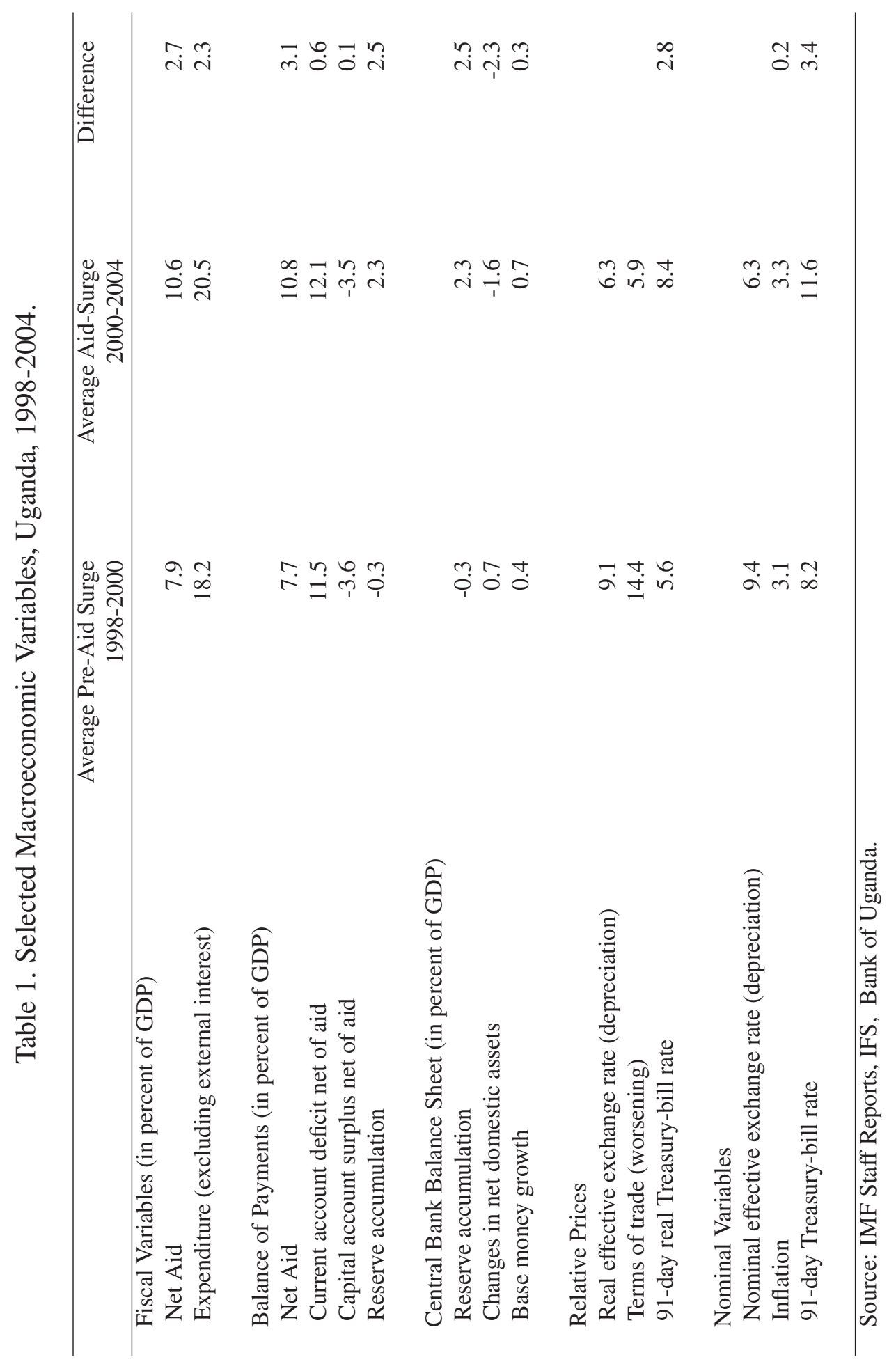


Table 2. Benchmark: Calibrated parameters.

\begin{tabular}{llll}
\hline Parameters & \multicolumn{3}{l}{ Parameters } \\
\hline$\beta$ & 0.99 & $\kappa_{A}$ & 0.078 \\
$\psi$ & 2 & $\kappa_{g}$ & 0.182 \\
$\varphi_{g}$ & 0.8 & $\kappa_{c}$ & 0.896 \\
$\zeta$ & 10 & $\rho_{A}$ & 0.87 \\
$\chi$ & 0.85 & $\rho_{R}$ & 0.9 \\
$\alpha$ & 0.7 & $v_{b}$ & 10000000 \\
$\varphi$ & 0.634 & $\mathfrak{p}$ & 0.42 \\
$\delta$ & 0.75 & $\phi_{\pi}$ & 1.5 \\
\hline
\end{tabular}




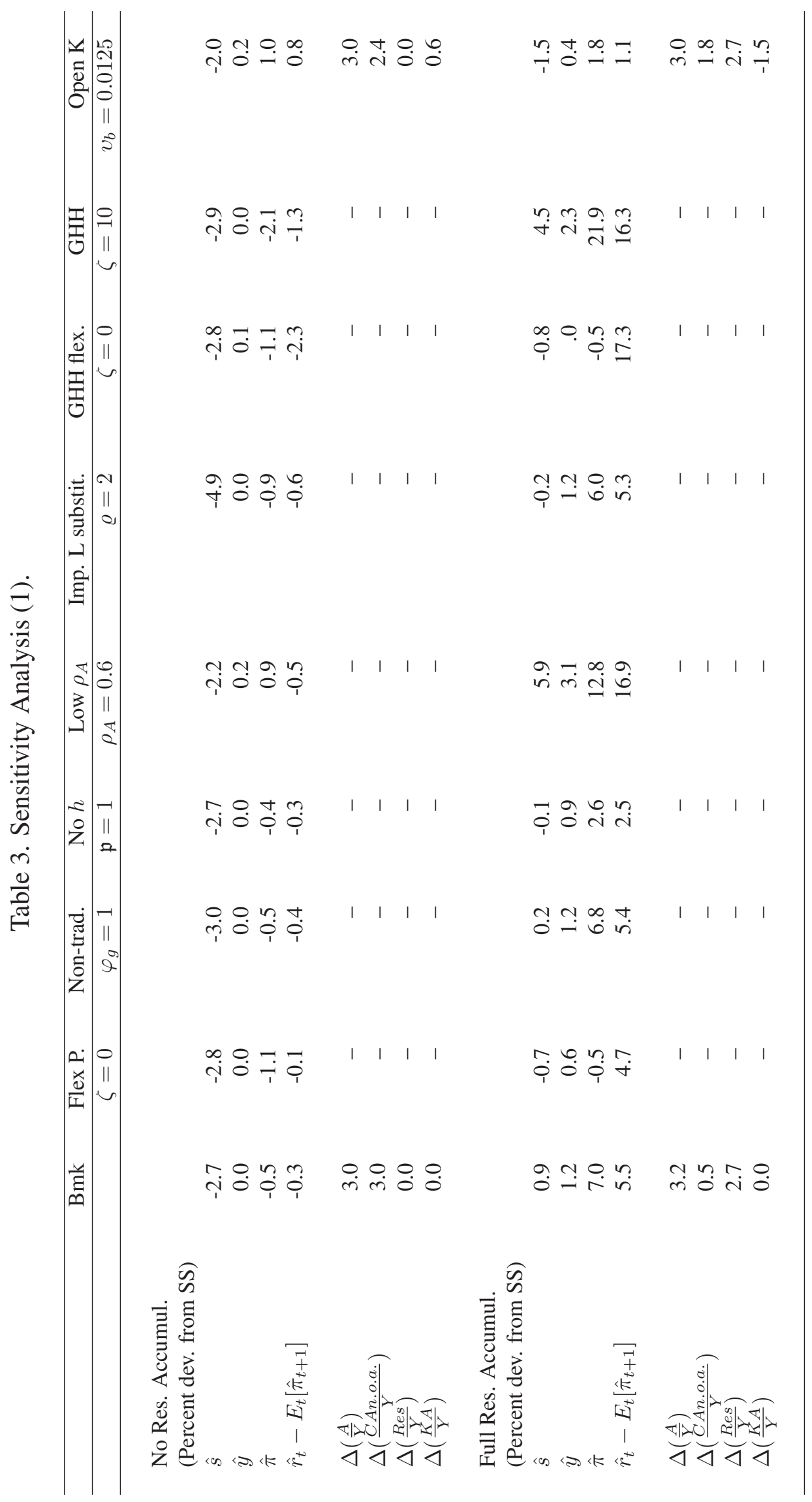




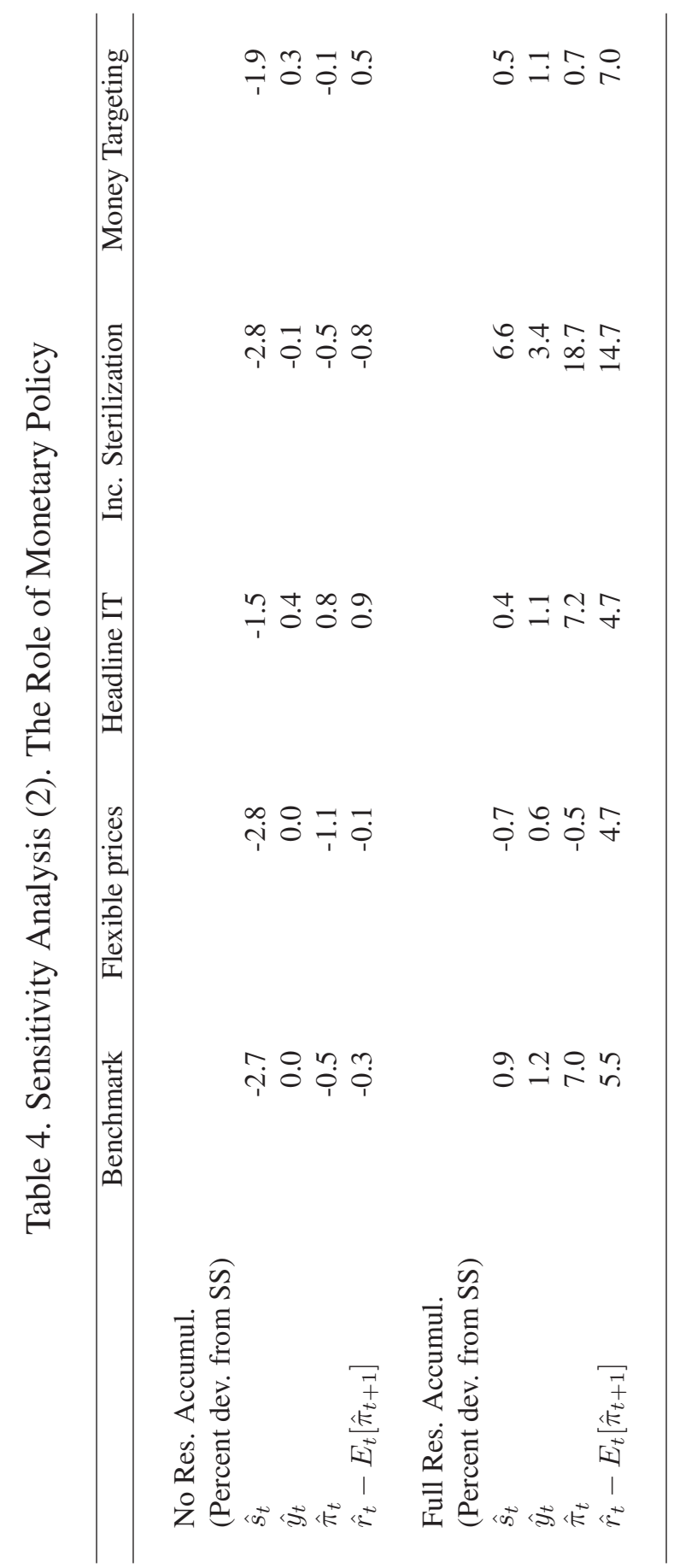


Figure 1. Possible Fiscal and Reserve Policy Combinations.

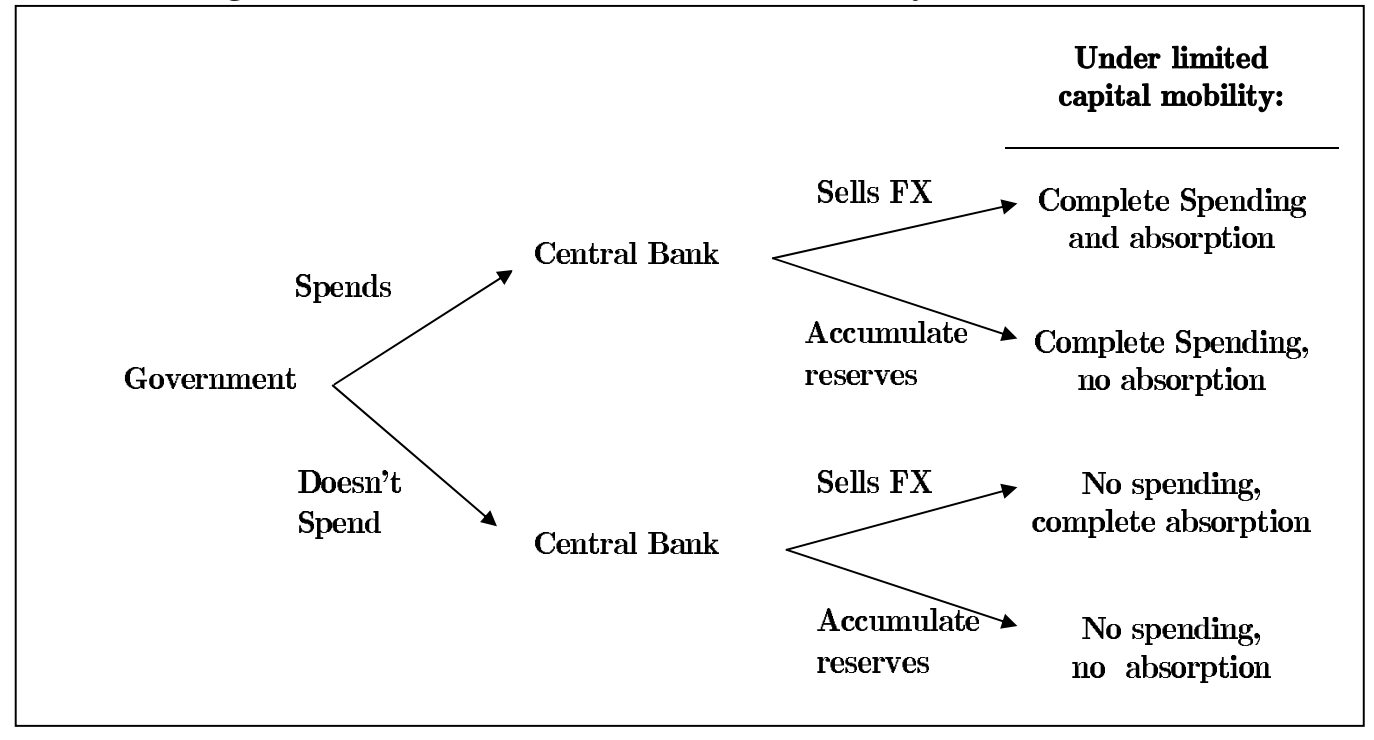


Figure 2. External Balance, Internal Balance and Labor Market Equilibrium

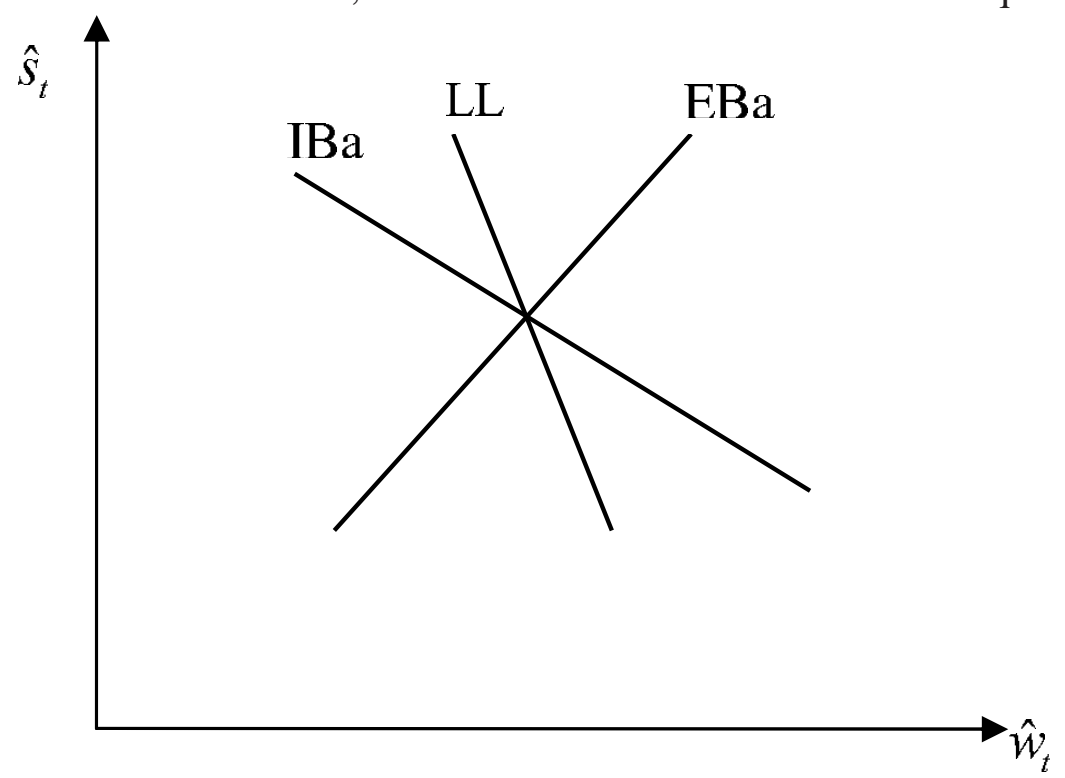


Figure 3. External and Internal Balance

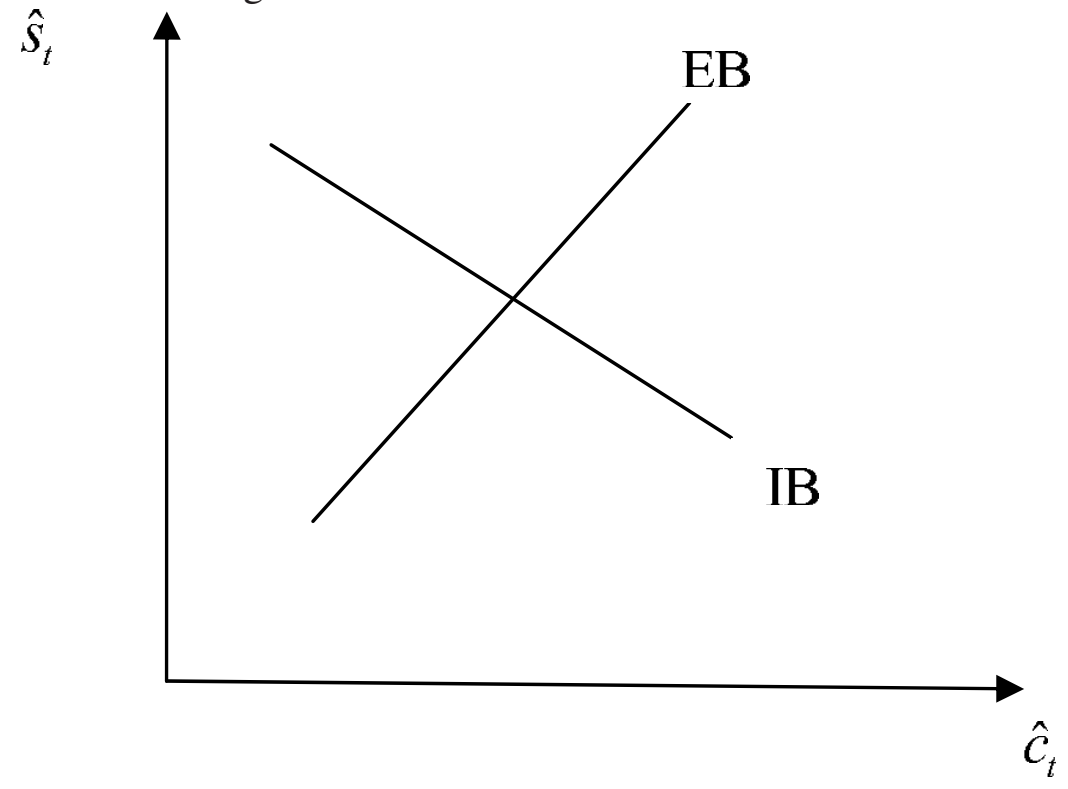


Figure 4. Alternative Spend and Absorb Scenarios

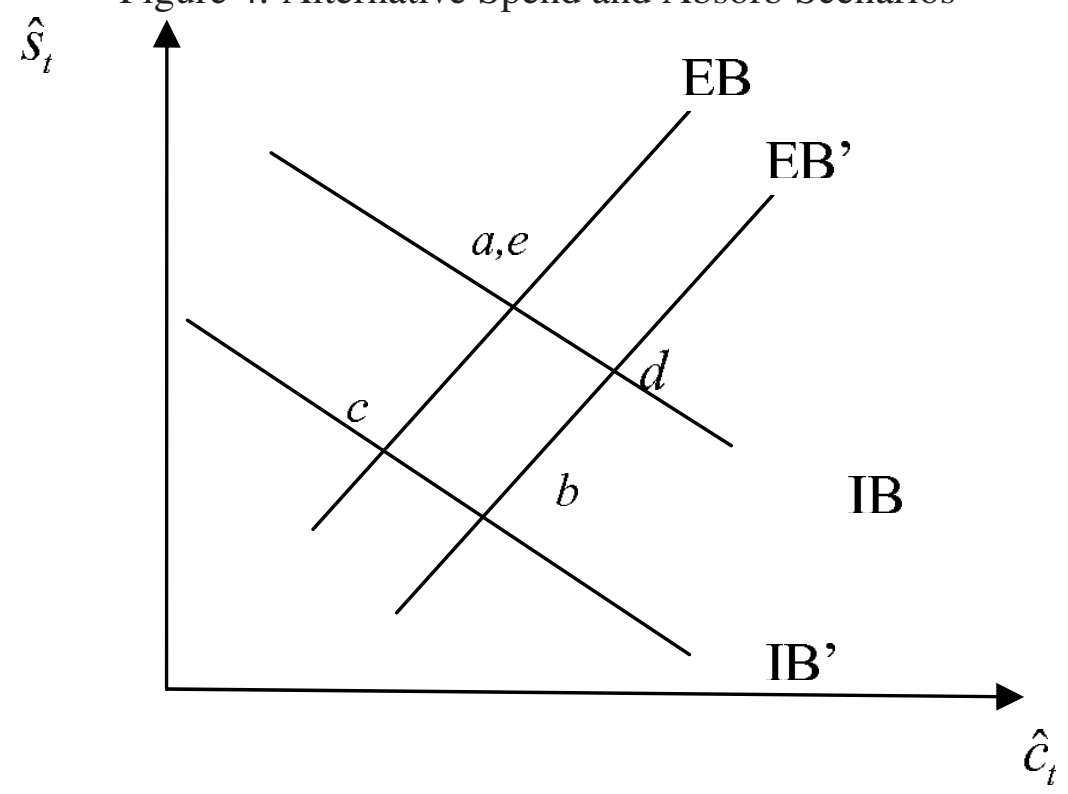


Figure 5. Alternative Spend and Absorb Scenarios (2)

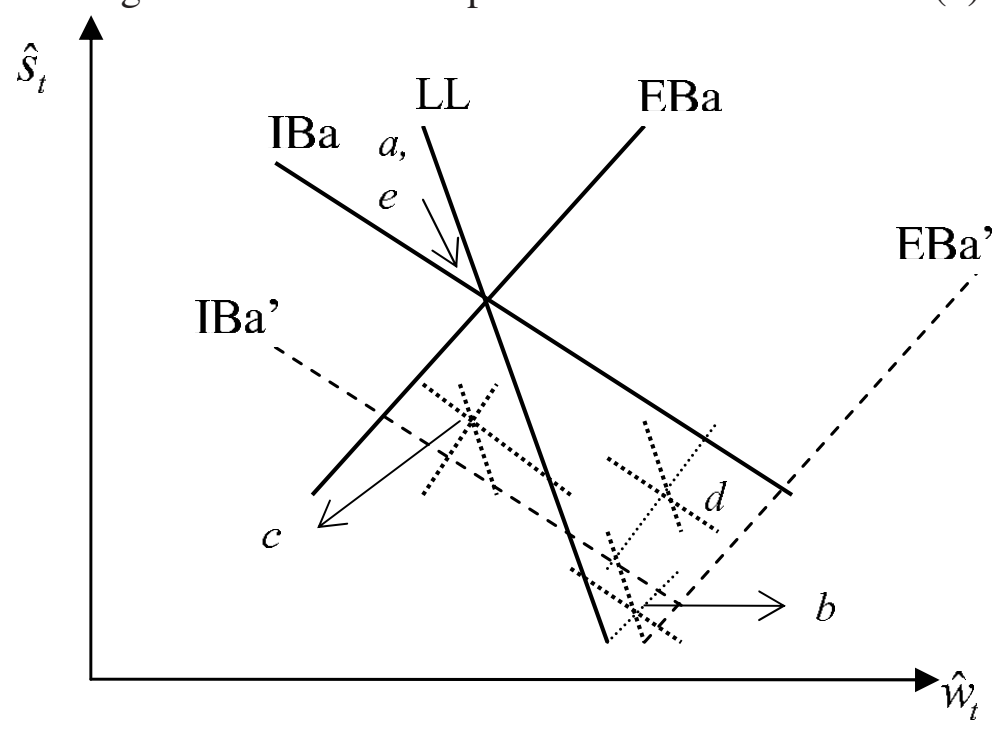


Figure 6. Alternative Spend and Absorb Scenarios (3): $\varphi_{g}<1$

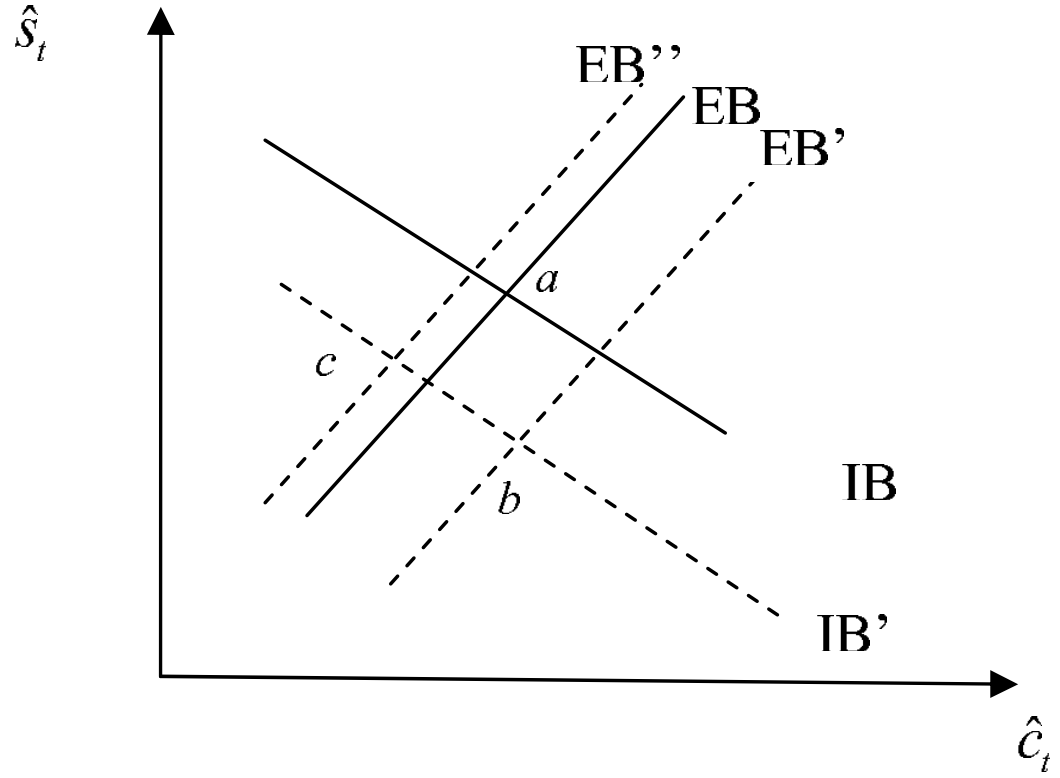


Figure 7. Alternative Reserve Policy Responses: Impact on $\hat{s}_{t}^{n}$ and $\hat{r}_{t}^{n}$

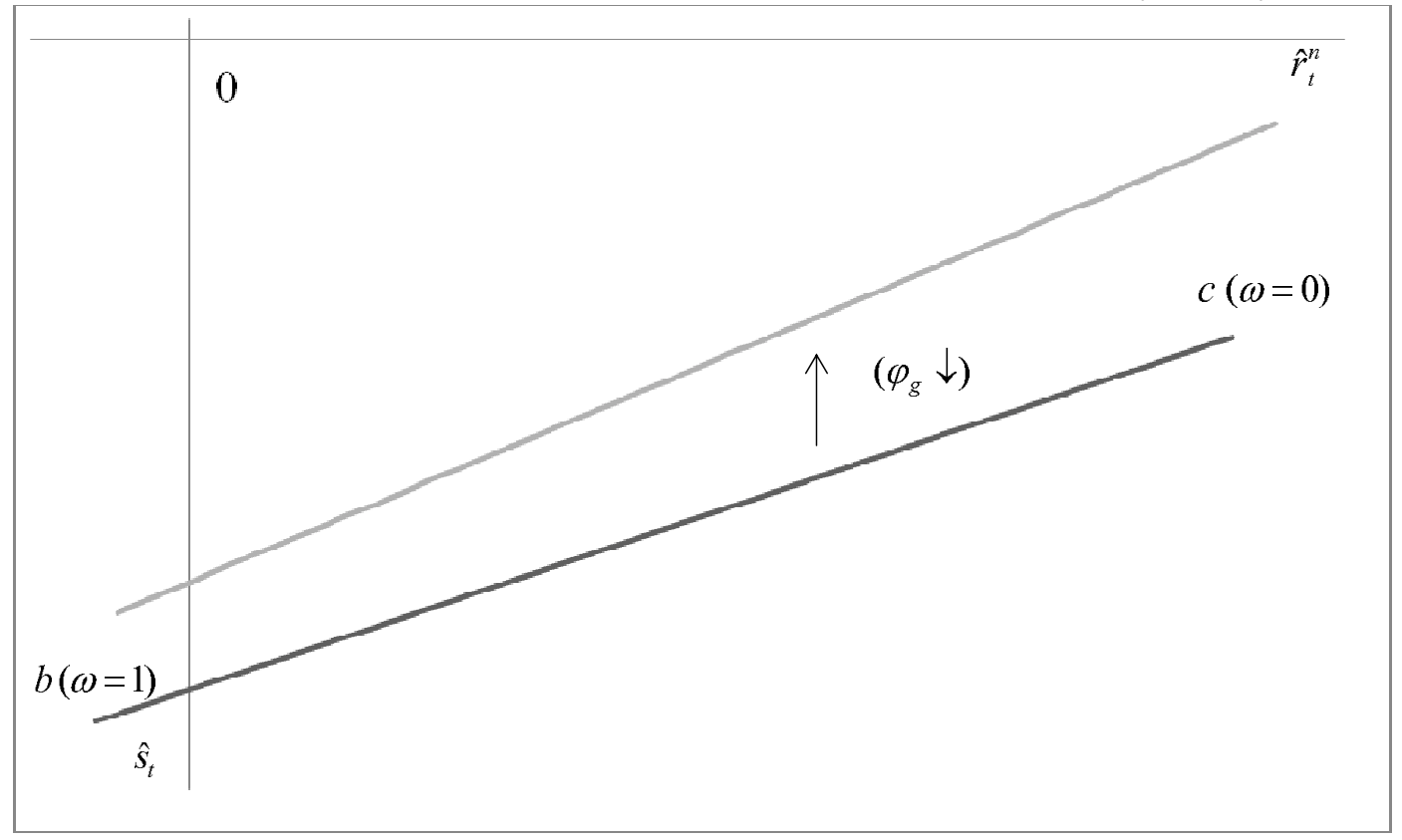


Figure 8. Spend and Absorb Scenario (Percent Deviations from Steady State)
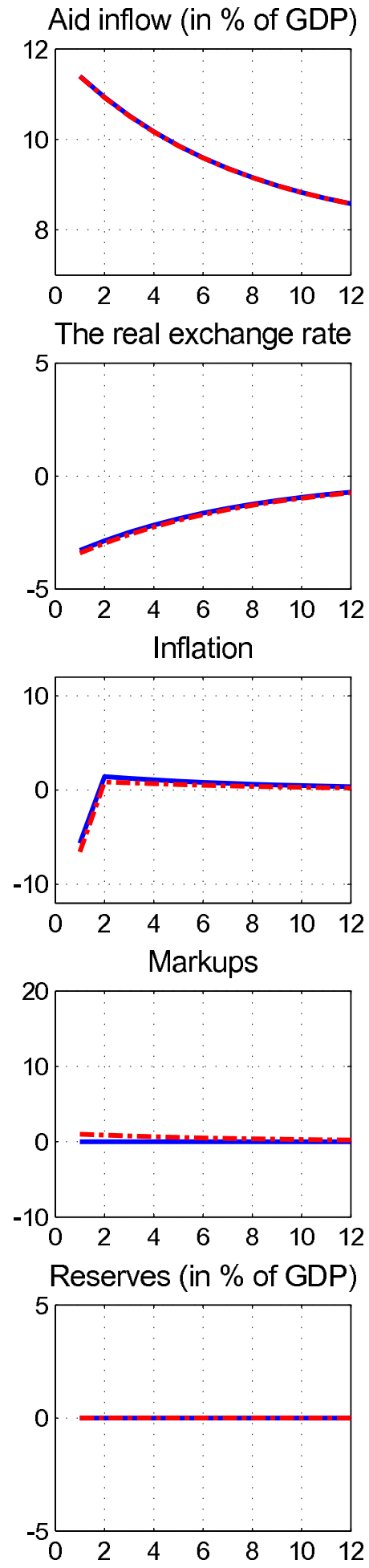

Govt. spending (in \% of GDP)

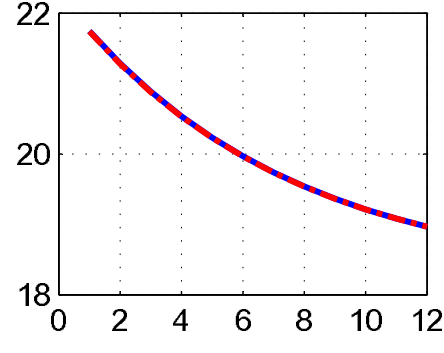

Real GDP

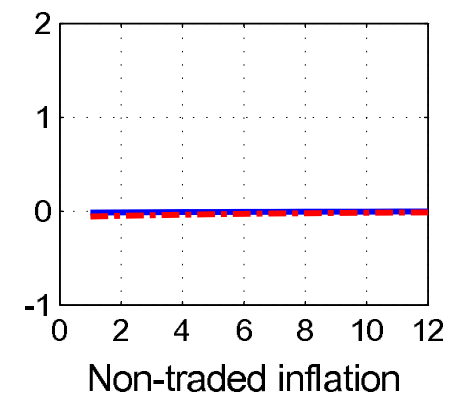

CA deficit (in \% of GDP)

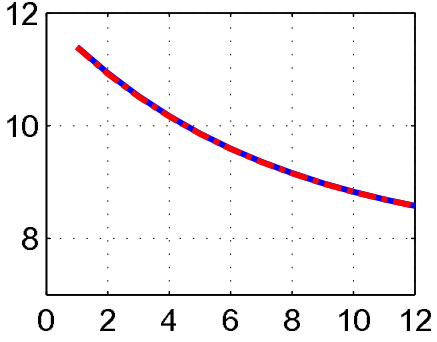

Consumption
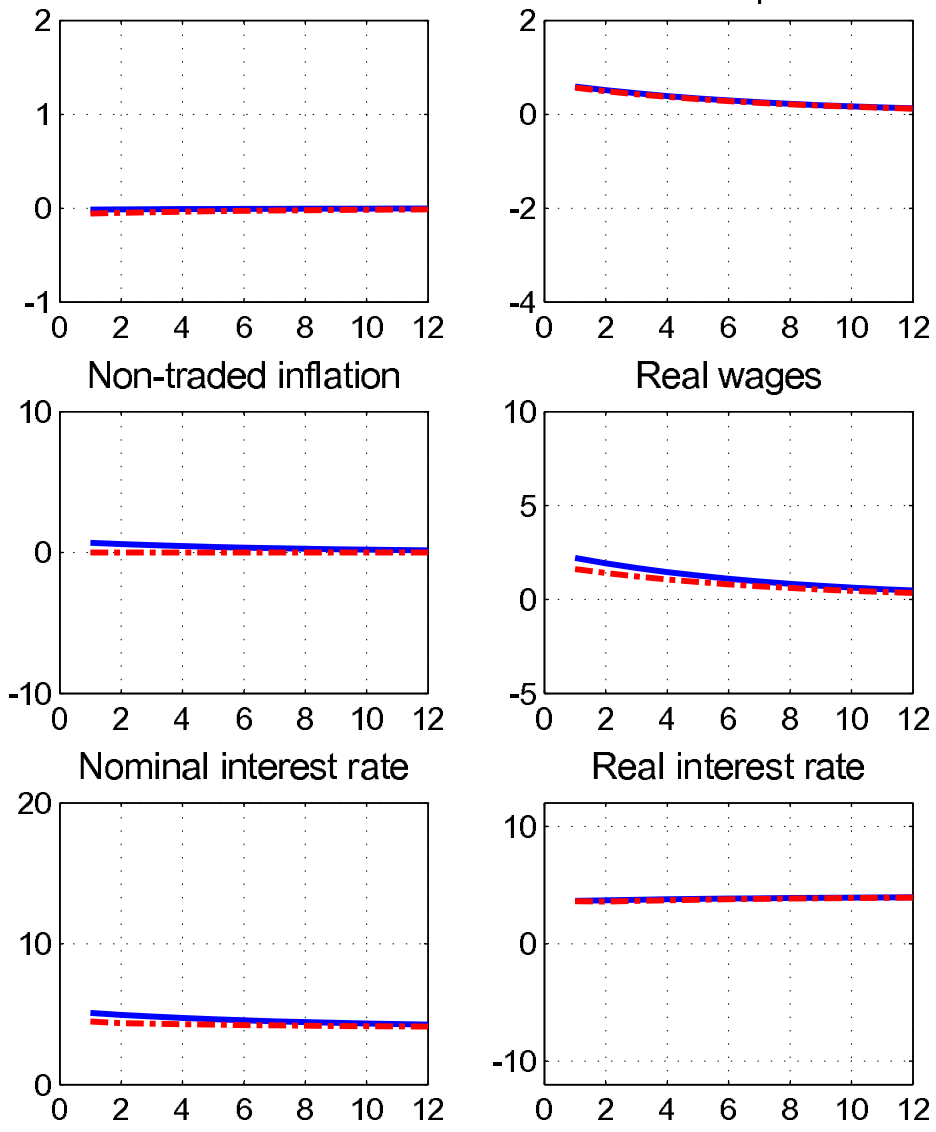

Out. govt debt (in \% of GDP)

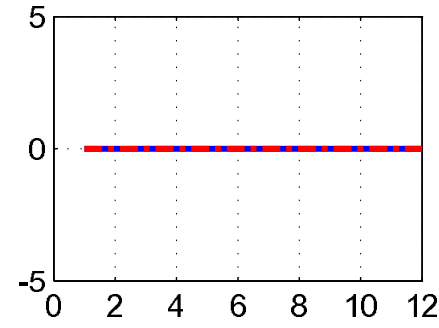


Figure 9. Spend, No Absorption Scenario (Percent Deviations from Steady State)
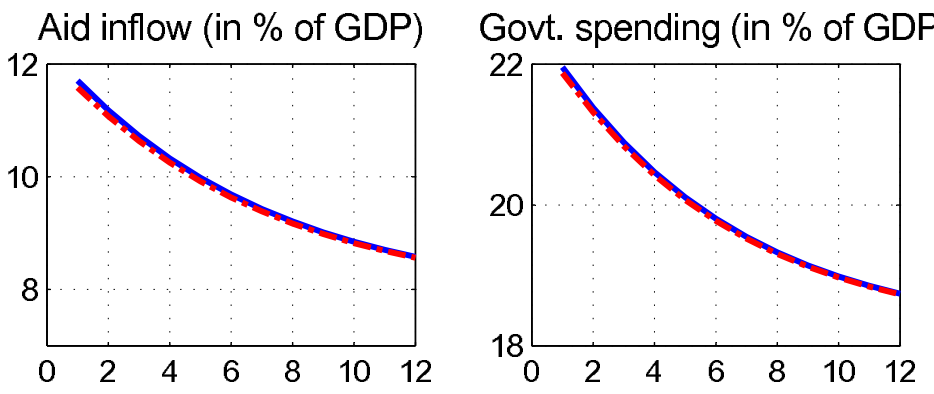

CA deficit (in \% of GDP)
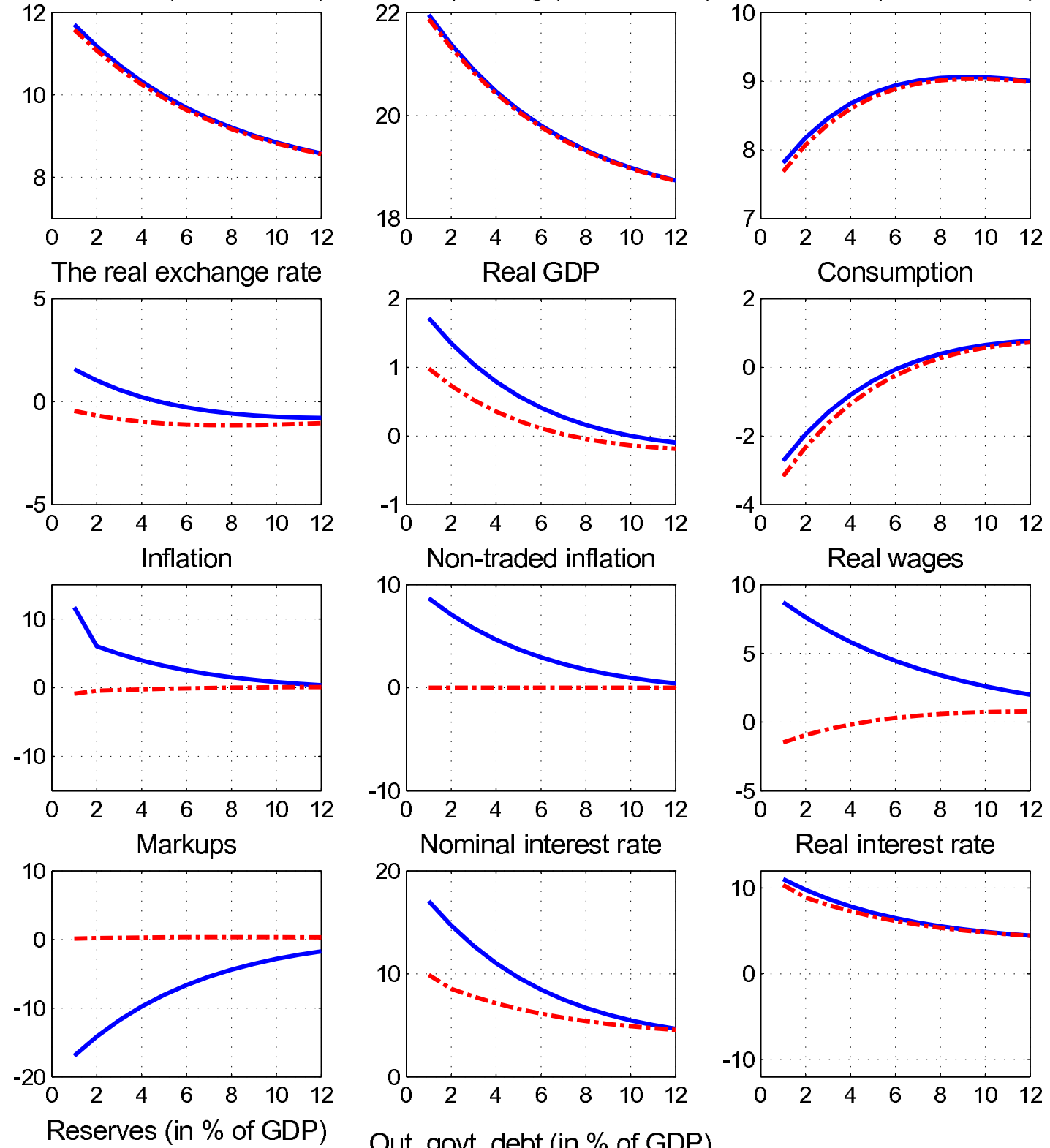

Out. govt. debt (in \% of GDP)
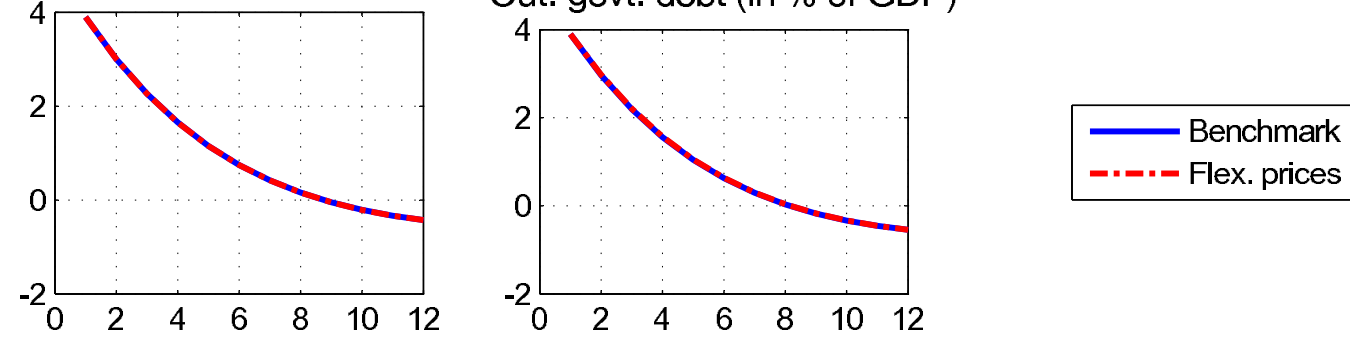
Figure 10. External Balance, Internal Balance and Labor Market Equilibrium revisited

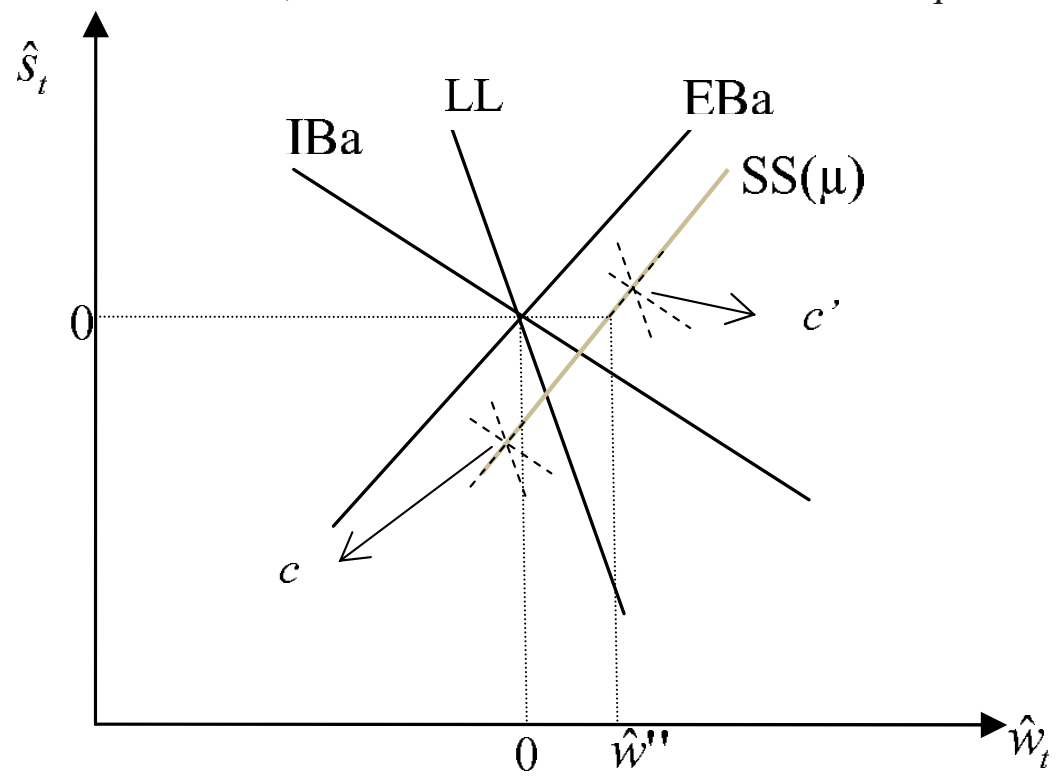




\section{REFERENCES}

Aoki, Kosuke, 2001, ’Optimal Monetary Policy Responses to Relative-Price Changes,' Journal of Monetary Economics, Vol. 48, pp. 55-80.

Adam, Christopher, Stephen O'Connell, Edward Buffie, and Catherine Pattillo, 2009, "Monetary Policy Rules for Managing Aid Surges in Africa," Review of Development Economics, Vol. 13, No. 3, pp. 464-490.

Agenor, Pierre-Richard and Peter Montiel, 2008, Development Macroeconomics, Princeton University Press. Princeton, NJ.

Arellano, Cristina, Ales Bulir, Timothy Lane, and Leslie Lipschitz, 2005. "The Dynamic Implications of Foreign Aid and Its Variability," Journal of Development Economics, Vol. 88, pp. 87-102.

Berg, Andrew, Shekhar Aiyar, Mumtaz Hussain, Shaun Roache, Tokhir Mirzoev, and Amber Mahone, 2007, 'The Macroeconomics of Scaling Up Aid: Lessons from Recent Experience," IMF Occasional Paper 253. (Washington: International Monetary Fund).

Berg, Andrew, Jan Gottschalk, Rafael Portillo, and Luis-Felipe Zanna, 2010, "The Macroeconomics of Gleneagles Aid Scaling-Up Scenarios," Unpublished manuscript.

Berg, Andrew, Rafael Portillo, and Filiz Unsal, 2010, "Optimal Adherence to Money Targets in Low-Income Countries," Unpublished manuscript.

Bouakez, Hafedh, Emanuela Cardia, and Francisco Ruge-Murcia, 2009, "The Transmission of Monetary Policy in a Multi-Sector Economy," International Economic Review, forthcoming.

Buffie, Edward, Christopher Adam, Stephen O'Connell, and Catherine Pattillo, 2008, "Riding the Wave: Monetary Responses to Aid Surges in Low-Income Countries," European Economic Review, Vol. 52, pp. 1378-1395.

Buffie, Edward, Christopher Adam, and Stephen O'Connell, 2010, 'Fiscal Inertia, Donor Credibility, and the Monetary Management of Aid Surges," Journal of Development Economics, forthcoming.

Burstein, Ariel, Martin Eichenbaum, and Sergio Rebelo, 2007, "Modeling Exchange Rate Passthrough After Large Devaluations," Journal of Monetary Economics, Vol. 54, No. 7, pp. 346-368.

Brock, Philip, 1996, 'International transfers, the relative price of non-traded goods, and the current account," Canadian Journal of Economics, Vol. 29, pp. 163-180.

Calvo, Guillermo, Carmen Reinhart, and Carlos Vegh, 1995, 'Targeting the Real Exchange Rate: Theory and Evidence," Journal of Development Economics Vol. 47, pp. 97-133.

Cerra, Valerie, Serpil Tekin, and Stephen J. Turnovsky, 2008, "Foreign Aid and Real Exchange Rate Adjustments in a Financially Constrained Dependent Economy," IMF Working Papers 08/204.

Chari, V. V., Patrick J. Kehoe, and Ellen R. McGrattan, 2005, "Sudden Stops and Output Drops," The American Economic Review Papers and Proceedings, Vol. 95, No. 2, pp. 381-387.

Chatterjee, Santanu, and Stephen J. Turnovsky, 2007, "Foreign aid and economic growth: The role of flexible labor supply," Journal of Development Economics, Vol. 84, pp. 507-533. 
Clarida, Richard, Jordi Galí, and Mark Gertler, 1999, 'The Science of Monetary Policy: A New Keynesian Perspective," Journal of Economic Literature, Vol. 37, No. 4, pp. 1661-1707.

Corsetti, Giancarlo André Meier and Gernot J. Müeller, 2009, ’Fiscal Simulus with Spending Reversals" CEPR Discussion Paper No. 7302.

Dagher, Jihad, Jan Gottschalk, and Rafael Portillo, 2010, "Oil Windfalls in a DSGE Model: The Case of Ghana," Unpublished manuscript.

Devereux, Michael and Gregor Smith, 2007, "Transfer problem dynamics: Macroeconomics of the Franco-Prussian War Indemnity," Journal of Monetary Economics, Vol. 54, pp. 2375-2398.

Dornbusch, Rudiger, 1974, "Real and Monetary Aspects of the Effects of Exchange Rate Changes," in Robert Z. Aliber, ed., National Monetary Policies and the International Financial System. Chicago, Il: University of Chicago Press.

Erceg, Chris, Dale W. Henderson, and Andrew T. Levin, 2000, ”Optimal Monetary Policy with Staggered Wage and Price Contracts," Journal of Monetary Economics, Vol. 46, pp. 281-313.

Galí, Jordi, 2008. Monetary Policy, Inflation and the Business Cycle, Princeton University Press. Princeton, NJ.

Galí, Jordi, J. David López-Salido, and Javier Vallés, 2007, "Understanding the Effects of Government Spending on Consumption," Journal of the European Economic Association, Vol. 5, No. 1, pp. 227-270.

Galí, Jordi, and Tommasso Monacelli, 2005, "Monetary Policy and Exchange Rate Volatility in a Small Open Economy Model,” Review of Economic Studies, Vol. 72, pp. 707-734.

Greenwood, Jeremy, Zvi Hercowitz, and Gregory W. Huffman, 1988, "Investment, Capacity Utilization, and the Real Business Cycle," The American Economic Review, Vol. 78, No. 3, pp. 402-417.

International Monetary Fund, 2008a, "Overview," in Regional Economic Outlook, Sub-Saharan Africa, chapter 1. Washington, DC: IMF.

International Monetary Fund, 2008b, "Monetary and Exchange Rate Policies in Sub-Saharan Africa," in Regional Economic Outlook, Sub-Saharan Africa, chapter 2. Washington, DC: IMF.

Kehoe, Timothy, and Kim J. Ruhl, 2009, 'Sudden Stops, Sectoral Reallocations, and the Real Exchange Rate," Journal of Development Economics, Vol. 89, pp. 235-249.

Keynes, John M. 1929, ’The German Transfer Problem,” Economic Journal, Vol. 39, pp. 1-7.

Khatkhate, Deena R., 1963, "Momey Supply Impact of National Currency Counterpart of Foreign Aid: an Indian Case," Review of Economics and Statistics, Vol. 45, No 1, pp. 78-83.

McCallum, Bennett T., 2001. "Monetary Policy Analysis in Models Without Money." The Federal Reserve Bank of St. Louis Review, Vol. 83, No. 4, pp. 145-160.

McDougall, I.A., 1965, "Non-Traded Goods and the Transfer Problem," Review of Economic Studies, Vol. 32, pp. 67-84. 
Monacelli, Tommasso and Roberto Perotti, 2009, "Fiscal Policy, Wealth Effects, and Markups," NBER Working Paper 14584.

Obstfeld, Maurice and Kenneth Rogoff, 1995, 'Exchange Rate Dynamics Redux," Journal of Political Economy, Vol. 103, No. 3, pp. 624-660.

Ohlin, Bertil, 1929, 'The Reparations Problem: A Discussion; Transfer Difficulties, Real and Imagined," Economic Journal, Vol. 39, pp. 172-183.

Prati, Alessandro and Thierry Tressel, 2006, "Aid Volatility and Dutch Disease: Is There a Role for Macroeconomic Policies?” IMF Working Papers 06/145.

Peiris, Shanaka J. and Magnus Saxegaard, 2007, ”An Estimated DSGE Model for Monetary Policy analysis in Low-Income Countries," IMF Working Papers 07/282.

Roemer, Michael, 1988, "The Macroeconomics of Counterpart Funds Revisited" World Development, Vol. 17, No. 6, pp. 796-807.

Rotemberg, Julio, 1982, "Monopolistic Price Adjustment and Aggregate Output," Review of Economic Studies, Vol. 49, pp. 517-531.

Salter, W.E.G., 1959, "Internal and External Balance: The Role of Price and Expenditure Effects," Economic Record, Vol. 35, No. 7, pp. 226-238.

Schmitt-Grohé, Stephanie and Martín Uribe, 2003, "Closing Small Open Economy Models,” Journal of International Economics, Vol. 61, pp. 163-185.

Steadman Group, 2009, ’Financial Access Survey for Financial Sector Deepening,” Presentation available at http://www.finscope.co.za/uganda.html.

Swan, T.W., 1960, "Economic Control in a Dependent Economy Model," Economic Record, Vol. 36, No. 7, pp. 51-66.

Woodford, Michael, 1999, ’Optimal Monetary Policy Inertia,” The Manchester School, Vol. 67 (Supplement), pp. 1-35.

Woodford, Michael, 2003, Interest and Prices, Princeton University Press. Princeton, NJ. 